\title{
Review \\ Engineered Nanostructured Photocatalysts for Cancer Therapy
}

\author{
Javier Bonet-Aleta ${ }^{1,2,3}\left(\mathbb{D}\right.$, Jose I. Garcia-Peiro ${ }^{1,2,3} \mathbb{D}$ and Jose L. Hueso $1,2,3, * \mathbb{D}$ \\ 1 Institute of Nanoscience and Materials of Aragon (INMA), Campus Río Ebro, Edificio I+D, \\ CSIC-Universidad de Zaragoza, C/Poeta Mariano Esquillor, s/n, 50018 Zaragoza, Spain; \\ jbaleta@unizar.es (J.B.-A.); joseignacio.garcia.peiro@gmail.com (J.I.G.-P.) \\ 2 Networking Research Center in Biomaterials, Bioengineering and Nanomedicine (CIBER-BBN), \\ Instituto de Salud Carlos III, 28029 Madrid, Spain \\ 3 Department of Chemical and Environmental Engineering, Campus Rio Ebro, University of Zaragoza, \\ C/María de Luna, 3, 50018 Zaragoza, Spain \\ * Correspondence: jlhueso@unizar.es
}

\section{check for}

updates

Citation: Bonet-Aleta, J.;

Garcia-Peiro, J.I.; Hueso, J.L.

Engineered Nanostructured

Photocatalysts for Cancer Therapy.

Catalysts 2022, 12, 167. https://

doi.org/10.3390/catal12020167

Academic Editors: Detlef

W. Bahnemann, Ewa Kowalska,

Ioannis Konstantinou,

Magdalena Janus, Vincenzo Vaiano,

Wonyong Choi and Zhi Jiang

Received: 31 December 2021

Accepted: 25 January 2022

Published: 28 January 2022

Publisher's Note: MDPI stays neutral with regard to jurisdictional claims in published maps and institutional affiliations.

Copyright: () 2022 by the authors Licensee MDPI, Basel, Switzerland. This article is an open access article distributed under the terms and conditions of the Creative Commons Attribution (CC BY) license (https:// creativecommons.org/licenses/by/ $4.0 /)$.

\begin{abstract}
The present review aims at highlighting recent advances in the development of photocatalysts devoted to cancer therapy applications. We pay especial attention to the engineering aspects of different nanomaterials including inorganic semiconductors, organic-based nanostructures, noble metal-based systems or synergistic hybrid heterostructures. Furthermore, we also explore and correlate structural and optical properties with their photocatalytic capability to successfully performing in cancer-related therapies. We have made an especial emphasis to introduce current alternatives to organic photosensitizers (PSs) in photodynamic therapy (PDT), where the effective generation of reactive oxidative species (ROS) is pivotal to boost the efficacy of the treatment. We also overview current efforts in other photocatalytic strategies to tackle cancer based on photothermal treatment, starvation therapy, oxidative stress unbalance via glutathione (GSH) depletion, biorthogonal catalysis or local relief of hypoxic conditions in tumor microenvironments (TME).
\end{abstract}

Keywords: photocatalysts; photodynamic therapy; reactive oxidative species; hybrids; nanocatalysts; noble-metal; upconversion; carbon

\section{Introduction}

Cancer is still one of the major causes of death and the projections for 2050 are not optimistic, estimating around $10 \mathrm{MM}$ worldwide deaths [1]. The improvement in the effectiveness of existing therapies or minimizing the side effects are considered as major goals in cancer research. Photodynamic therapy (PDT) aims at treating cancer with the aid of a photosensitizer (PS) and a light irradiation source of suitable energy to activate endogenous $\mathrm{O}_{2}$ to produce reactive oxygen species (ROS) which subsequently provoke cell apoptosis [2]. The main advantage of this synergy is the selectivity provided by the local irradiation dosing which places PDT as a minimally invasive therapy. The light source must accomplish two main requirements: (i) the wavelength must be in the range between red $(660 \mathrm{~nm})$ and NIR-NIR II $(1100 \mathrm{~nm})$ to ensure a large tissue penetration [3] and (ii) the energy of the employed light must match with the excitation energy of the selected PSs. PSs consist of organic molecules (e.g., porfimer sodium, aminolevulinic acid, talaporfin, temoporfin or verteporfin [4]) which are being evaluated in clinical trials. These PSs are currently yielding promising results in diverse tumors [5] including esophageal [6], breast cancer [7] or melanoma [8]. However, organic-based PSs face several challenges: (i) their molecular structure is mainly based on highly conjugated $\pi$-systems formed from aromatic rings which limits their solubility in aqueous media and in biological environments [2,9]; (ii) The generated ROS, once the PS is activated with light, can react with the PS, modifying its molecular structure and hence their energetic levels. As a result, the modified PSs will not be able to interact with the light, losing its photo-activity [2]; and (iii), when PSs are 
loaded on carriers, they suffer from uncontrollable loading/release, which may affect to healthy cells placed nearby the tumor region [10-12].

In the recent years, several photoactive nanocatalysts have emerged as promising candidates in phototherapy overcoming the challenges faced by organic PSs. Through a plethora of synthetic strategies, the surface of nanoparticles can be tailored with different ligands/agents to promote their stability in physiological media. Moreover, their structured nature confer them more robustness towards ROS self-production. Finally, their nanosized dimensions favor their accumulation in solid tumors due to enhanced permeability and retention (EPR) effects [13].

Organic molecules present an electronic structure organized in molecular orbitals where the energy levels own discrete values (Figure 1a) [14]. The light employed in PDT aims to interact with electrons occupying the highest occupied molecular orbital (HOMO) and promote its excitation to the lowest unoccupied molecular orbital (LUMO) [15]. This excited electron may transfer its excess of energy to a nearby $\mathrm{O}_{2}$ molecule, change its electronic multiplicity and hence form singlet oxygen ${ }^{1} \mathrm{O}_{2}$ (process known as PDT Type I). Alternatively, it can be directly transferred to $\mathrm{O}_{2}$ in order to boost formation of different ROS species such as superoxide anion, hydrogen peroxide or hydroxyl radicals (e.g., $\bullet \mathrm{O}_{2}{ }^{-}$, $\mathrm{H}_{2} \mathrm{O}_{2}$ or $\bullet \mathrm{OH}$ ) (described as PDT Type II).

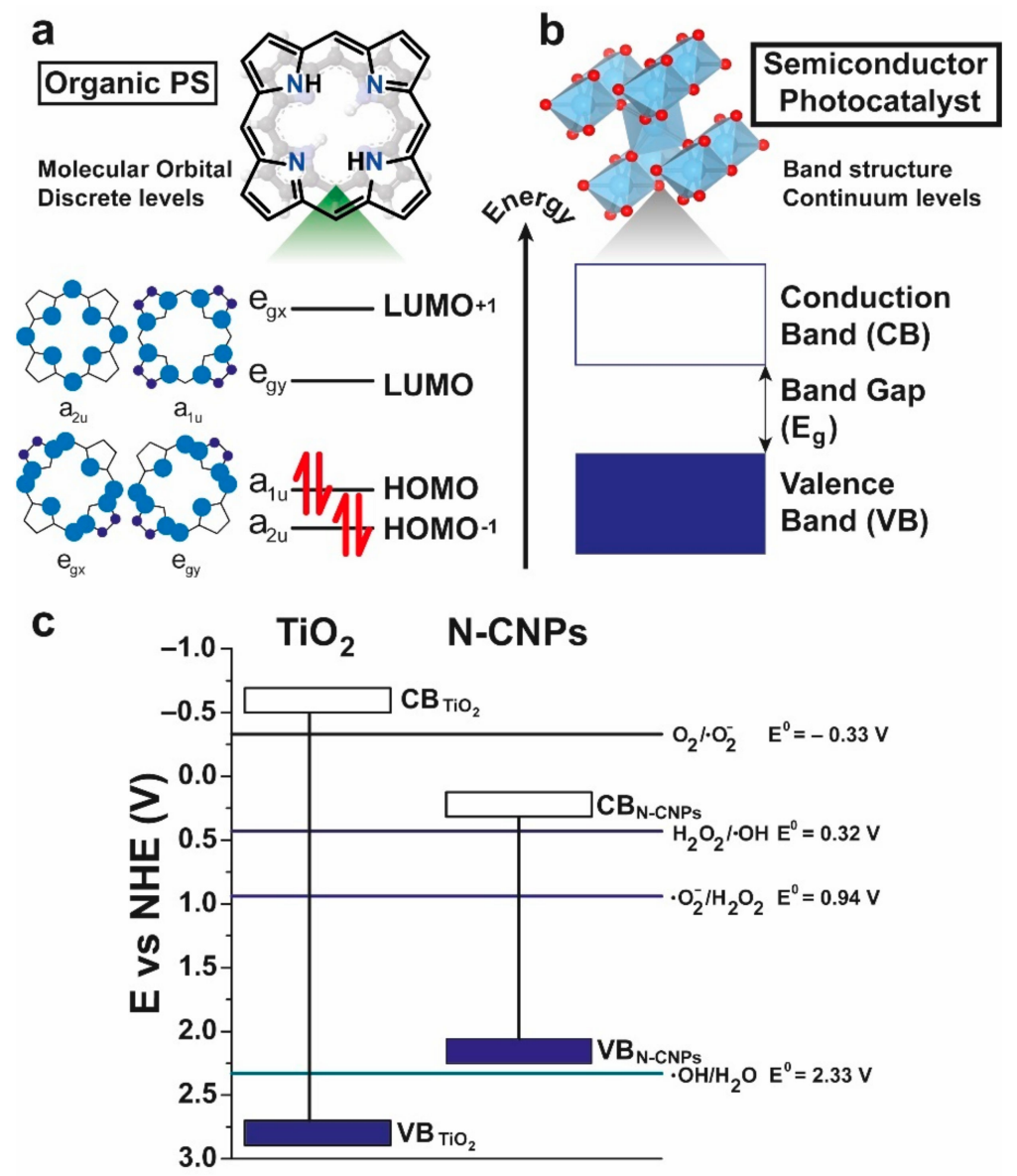

Figure 1. Differences in the electronic structure between organic PSs and semiconductor photocatalysts: $(\mathbf{a}, \mathbf{b})$ Organic molecules organize their electronic levels in molecular orbitals with discrete values in contradistinction to a classic solid semiconductor where the electronic levels acquire continuum values in bands. The most interesting bands regarding photocatalysis are the highlighted VB and $\mathrm{CB}$, which are separated by $\mathrm{E}_{\mathrm{g}}$; (c) Influence of the position of $\mathrm{VB}$ and $\mathrm{CB}$ in the photocatalytic products. For example, the photogenerated $h^{+}$of a VB positioned above $E^{0}\left(\bullet \mathrm{OH} / \mathrm{H}_{2} \mathrm{O}\right)$ will not possess the enough potential to oxidize $\mathrm{H}_{2} \mathrm{O}$ into $\bullet \mathrm{OH}$. 
Unlike organic molecules, nanostructured semiconductor photocatalysts possess a band structure where the energy levels have continuum values [16]. The bands analogous to $\mathrm{HOMO}$ and LUMO levels in organic molecules are the valence (VB) and conduction bands $(\mathrm{CB})$, respectively. They are separated by an energy corresponding to an energy band gap $\left(E_{g}\right)$ in the case of semiconductors (Figure $\left.1 b\right)$. Thus, the photocatalytic event occur when a photon with larger energy than $E_{g}$ excites an electron $\left(e^{-}\right)$from VB to $C B$, generating electron/hole $\left(\mathrm{e}^{-} / \mathrm{h}^{+}\right)$pairs which can react with surrounding molecules such as $\mathrm{O}_{2}$ and $\mathrm{H}_{2} \mathrm{O}$ to generate ROS [16]. For photocatalytic therapy purposes, the energy band engineering of nanomaterials must be framed within the range of the biocompatible window (650-1100 nm). Although the $E_{g}$ value is a key factor in the selection of the photocatalyst, the position of their respective bands is equally essential towards a successful ROS generation [17-19]. Considering the reduction standard potentials vs. a standard hydrogen electrode (SHE) at $\mathrm{pH}=7$ of different oxygen containing species (Figure 1c) [20], the bands of two different photocatalysts (inorganic $\mathrm{TiO}_{2}$ and organic $\mathrm{N}$-containing carbon dots) are compared with the $\mathrm{E}^{0}$ of the half-reactions to produce ROS. Since the VB and CB of $\mathrm{TiO}_{2}$ possess large potential levels, the reactivity of the photogenerated electron-hole pair $\left(\mathrm{e}^{-} / \mathrm{h}^{+}\right)$in $\mathrm{TiO}_{2}$ is large, being able to oxidize $\mathrm{H}_{2} \mathrm{O}$ into $\bullet \mathrm{OH}$ and reduce $\mathrm{O}_{2}$ into $\bullet \mathrm{O}_{2}{ }^{-}$. Despite the efficiency of $\mathrm{TiO}_{2}$ as a photocatalyst, its wide $\mathrm{E}_{\mathrm{g}}(3.2 \mathrm{eV})$ burdens its direct application for in vivo photocatalysis, as the energy of the required light is $385 \mathrm{~nm}$ and its penetration in tissues is close to zero [3]. On the other hand, while nitrogen-doped carbon dots (N-CDs) with a narrower $\mathrm{E}_{\mathrm{g}}(1.63 \mathrm{eV})$ can be activated with $650 \mathrm{~nm}$ biocompatiblelight, the the position of their VB prevent the formation of hydroxyl radicals $(\bullet \mathrm{OH})$ from $\mathrm{H}_{2} \mathrm{O}$, a desired ROS from the therapeutic point of view. Figure 1 summarizes two examples of well-known standing alone photocatalysts that are not suitable for PDT but might work if conveniently engineered to form a hybrid heterostructure.

The use of nanostructured photocatalysts does not only tackles ROS generation to perform PDT. Recent literature reports also confer on them the capability to catalyze water splitting (i.e., $\mathrm{O}_{2}$ production from $\mathrm{H}_{2} \mathrm{O}$ ) [21], glutathione (GSH) oxidation [22] and $\mathrm{H}_{2}$ production [23]. Since PDT employs $\mathrm{O}_{2}$ as the major electron/energy acceptor to generate ROS, its intrinsic scarcity in the tumor environment typically burdens the full potential of this therapy. The aberrant growth of tumors provokes an irregular creation of blood vessels causing limited $\mathrm{O}_{2}$ supply [24]. Thus, the in-situ generation of $\mathrm{O}_{2}$ is considered a major advantage for a photocatalyst because of the continuous photogeneration of ROS in a hypoxic environment [25]. Regarding GSH, its key role as the main antioxidant molecule in animal cells is responsible for ROS counterbalance in diverse metabolic routes [26]. The major metabolic activity in cancer cells provokes an overexpression of GSH (up to mM [27]) and a larger dependency of their levels. Therefore, the inhibition of GSH synthesis or its direct removal through catalytic processes [22] guarantees a ROS disruption in the cell leading to its apoptosis. Finally, it has been recently demonstrated that the generation of $\mathrm{H}_{2}$ inside a tumor cell may induce a disruption of the mitochondria, causing a disarrangement in ATP levels (Figure 2).

Noble metals have also attracted great attention in multiple biomedical applications due to their unique properties in terms of biocompatibility, stability and optical response [28-30]. A wide variety of applications have been demonstrated for novel metals to act as optimal nanoagents to selectively enhance well-established or developed therapies. It has been shown how metal-based nanomaterials can improve radiotherapy (RT) [31], sonodynamic therapy (SDT) [32] or electrodynamic therapy (EDT) [33]. Smart nanoplatforms have been designed to effectively respond to the tumor microenvironment (TME), simulate enzyme properties [34,35], act as drugs delivery systems [36] or as immunonanocarriers [37], perform starvation therapy (ST) [38] or activate designed prodrugs to perform in vivo biorthogonal catalysis [39,40]. In addition, light-induced therapies have been also taken advantage of noble metal nanoparticles to selectively enhance therapy performance. In the last few years, noble metal-based nanoparticles have risen as one of the most promising 
alternatives to selectively promote light-triggered therapies such as photothermal therapy (PTT) [41,42] or PDT [43].

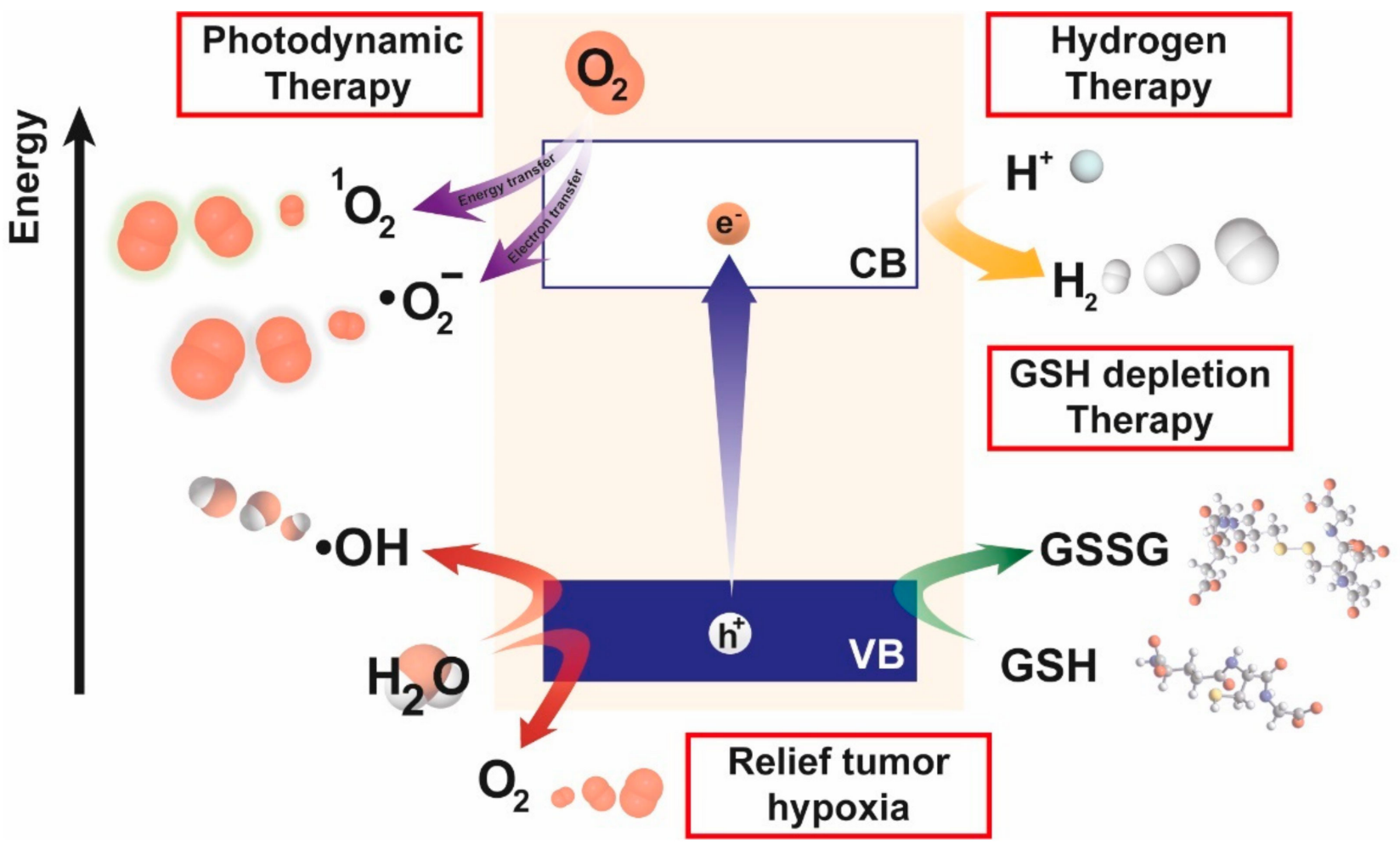

Figure 2. Photocatalytic reactions performed by nanostructured catalysts of interest for cancer therapy. Most of these photocatalysts are reported to produce $\mathrm{ROS}$ (i.e., ${ }^{1} \mathrm{O}_{2}, \bullet \mathrm{OH}$ and $\bullet \mathrm{O}_{2}{ }^{-}$), but recent works endorse these photocatalysts the capability to generate $\mathrm{H}_{2}$ or $\mathrm{O}_{2}$ through the reaction of aqueous $\mathrm{H}^{+}$ with photogenerated $\mathrm{e}^{-}$and the consumption of photogenerated $\mathrm{h}^{+}$by $\mathrm{H}_{2} \mathrm{O}$ molecules, respectively. Moreover, some photocatalysts may also transform intracellular GSH into GSSG via $\mathrm{h}^{+}$consumption. These reactions are added to the toolbox employed by photocatalysts to achieve a more efficient cancer therapy.

This review focuses on the different engineering strategies adopted in recent years to enhance the photocatalytic response of nanoparticles for cancer therapy. We tackle the most recent efforts to improve the local $\mathrm{O}_{2}$ supply in tumor environments, the elimination of GSH to maximize the action of ROS species and overall, we emphasize the role of different photocatalysts beyond organic PSs working on PDT. We overview the exploited approaches to engineer active photocatalysts including: (1) the design of narrow $\mathrm{E}_{\mathrm{g}}$ photocatalysts; (2) using noble-metal based nanostructures; (3) the combination of different photocatalyst to create diverse heterojunctions (type-II heterojunctions, Z-schemes and metal-semiconductor heterojunctions).

\section{Use of Low Energy Bandgap Photocatalysts}

Classical semiconductor photocatalysts such as $\mathrm{ZnO}$ or $\mathrm{TiO}_{2}$ are highly efficient to induce ROS generation in aqueous media [44], but their large $\mathrm{E}_{\mathrm{g}}$ (3.4 and $3.2 \mathrm{eV} \mathrm{[45],}$ respectively) limits their application in PDT. In addition, when the particle size decreases down to few nanometers, the resulting $E_{g}$ of the nanomaterial tends to be wider. The quantum confinement of the electrons present in the nanoparticle induces an energy shift of the VB and CB levels towards more positive and negative potentials, respectively [46]. In the recent years, there have been multiple attempts to obtain novel photocatalysts with suitable $\mathrm{E}_{\mathrm{g}}$ as alternatives for PDT application (Table 1). 
Table 1. Different photocatalytic materials with low $E_{g}$ applied for PDT.

\begin{tabular}{|c|c|c|c|c|}
\hline Material & $\begin{array}{c}\text { Measured Band } \\
\text { Gap }\left(E_{g}\right)(e V)\end{array}$ & $\begin{array}{l}\text { Light Irradiation } \\
(\mathrm{nm})\end{array}$ & $\begin{array}{l}\text { Catalysis } \\
\text { Products }\end{array}$ & Reference \\
\hline $\mathrm{BP} \mathrm{NSs}^{\mathrm{a}}$ & 2.0 & 660 & ${ }^{1} \mathrm{O}_{2}$ & [47] \\
\hline $\mathrm{MoS}_{2} \mathrm{QDs}$ & 1.875 & 630 & $\bullet \mathrm{O}_{2}^{-}$ & {$[48]$} \\
\hline $\mathrm{Cs}_{\mathrm{x}} \mathrm{WO}_{3} \mathrm{NRs}$ & & $880+1064$ & ${ }^{1} \mathrm{O}_{2}$ & [49] \\
\hline $\mathrm{BP}_{\mathrm{QDs}}{ }^{\mathrm{b}}$ & & $625+880$ & ${ }^{1} \mathrm{O}_{2}$ & [50] \\
\hline $\mathrm{RPCN}^{\mathrm{c}}$ & 1.71 & 808 & GSSG, $\mathrm{H}_{2}$ & [51] \\
\hline $\mathrm{TiSe}_{2}$ & 1.77 & 808 & $\begin{array}{c}\mathrm{GSSG}_{,} \bullet \mathrm{O}_{2}{ }^{-}, \\
\bullet \mathrm{OH}\end{array}$ & [52] \\
\hline $\mathrm{B}-\mathrm{TiO}_{2}$ & - & 808 & $\bullet \mathrm{OH},{ }^{1} \mathrm{O}_{2}$ & [53] \\
\hline $\mathrm{G}-\mathrm{TiO}_{2}$ & - & 980 & $\bullet \mathrm{OH},{ }^{1} \mathrm{O}_{2}$ & {$[54]$} \\
\hline $\mathrm{C}_{5} \mathrm{~N}_{2} \mathrm{NPs}$ & 1.63 & $650+808$ & $\mathrm{O}_{2},{ }^{1} \mathrm{O}_{2}$ & [21] \\
\hline$g-C_{3} N_{4}-G O x^{d}$ & 2.30 & 630 & $\mathrm{O}_{2}$ & [55] \\
\hline SWCN $^{\mathrm{e}}$ & - & 808 & $\bullet \mathrm{O}_{2}^{-},{ }^{1} \mathrm{O}_{2}$ & {$[56]$} \\
\hline Nanographene & - & 980 & ${ }^{1} \mathrm{O}_{2}$ & [57] \\
\hline $\mathrm{C}_{60}-\mathrm{IONP}^{\mathrm{f}}$ & - & 532 & ROS & [58] \\
\hline N-CDs & - & 740 & $\mathrm{H}_{2} \mathrm{O}_{2}, \bullet \mathrm{O}_{2}^{-}$ & [59] \\
\hline N-CDs-TPP g & - & 625 & ${ }^{1} \mathrm{O}_{2}$ & {$[60]$} \\
\hline $\mathrm{Zr}-\mathrm{FeP}$ & - & 635 & ${ }^{1} \mathrm{O}_{2}$ & [61] \\
\hline $\mathrm{TCPC}-\mathrm{UiO}^{\mathrm{h}}$ & - & 635 & ${ }^{1} \mathrm{O}_{2}$ & {$[62]$} \\
\hline $\mathrm{W}_{2} \mathrm{C}$ & 0 & 1064 & $\bullet \mathrm{OH},{ }^{1} \mathrm{O}_{2}$ & {$[63]$} \\
\hline $\mathrm{Mo}_{2} \mathrm{C}$ & 0 & 808 & $\bullet \mathrm{OH}, \mathrm{O}_{2}$ & [64] \\
\hline
\end{tabular}

${ }^{a}$ Black Phosphorous Nanosheets; ${ }^{\mathrm{b}}$ Quantum Dots; ${ }^{\mathrm{c}}$ Red Polymeric Carbon Nitride; ${ }^{\mathrm{d}}$ Glucose oxidase; ${ }^{\mathrm{e}}$ Single Walled Carbon Nanotube; ${ }^{\mathrm{f}}$ Iron Oxide Nanoparticle; ${ }^{\mathrm{g}}$ Mono-hydroxylphenyl triphenylporphyrin; ${ }^{\mathrm{h}}$ Tetratopic Chlorin-Universitetet i Oslo.

\subsection{Nanostructured Inorganic Photocatalysts}

Black phosphorous (BP) represents one of the first examples of a nanostructured inorganic photocatalyst applied to PDT $[47,50,65]$. Controlling the dimensions and morphology of BP enables the correct matching of the incident irradiation source (suitable for a biocompatible window) with the tunable $\mathrm{E}_{\mathrm{g}}$. $\mathrm{BP}$ can vary its $\mathrm{E}_{\mathrm{g}}$ from $0.3 \mathrm{eV}$ (in bulk) to a $2.0 \mathrm{eV}$ for a BP monolayer [66]. Wang et al. [47] demonstrated the capability of BP nanosheets to yield ${ }^{1} \mathrm{O}_{2}$ from $\mathrm{O}_{2}$ using a $660 \mathrm{~nm}$ laser in human MDA-MB-231 breast cancer cells. In vivo results also showed the photocatalytic activity of $\mathrm{BP}$ and its efficacy inhibiting tumor growth with a combination of $660 \mathrm{~nm}$ irradiation and a dose of BP of $0.6 \mathrm{mg} / \mathrm{kg}$ (Figure 3a). BP QDs have also been successfully applied to the photocatalytic conversion of $\mathrm{O}_{2}$ into ${ }^{1} \mathrm{O}_{2}$ for PDT [50], using a combination of 625 and $808 \mathrm{~nm}$ light. Both BP nanostructures, NSs and QDs, displayed good biocompatibility in vivo [47,50]. Although classical $\mathrm{TiO}_{2}$ is not suitable for PDT due its narrow $\mathrm{E}_{\mathrm{g}}$, it can be chemically modified to allow the use of biocompatible irradiation to perform photocatalysis. The Shi group [53] developed black- $\mathrm{TiO}_{2}$ $\left(\mathrm{B}-\mathrm{TiO}_{2}\right)$ starting from $\mathrm{P} 25$ nanoparticles through the reduction of $\mathrm{TiO}_{2}$ using aluminum at low temperature. In another study, they also prepared green- $\mathrm{TiO}_{2}\left(\mathrm{G}-\mathrm{TiO}_{2}\right)$ nanoparticles by applying an ultrasonication process to $\mathrm{B}^{-\mathrm{TiO}_{2}}$ [54]. Both materials demonstrate an encouraging PDT capability under 808 and $980 \mathrm{~nm}$ for $\mathrm{B}_{-} \mathrm{TiO}_{2}$ and $\mathrm{G}-\mathrm{TiO}_{2}$, respectively (Figure $3 \mathrm{~b}$ ). Photocatalysts with a metallic-like electronic band structure (i.e., $\mathrm{E}_{\mathrm{g}}$ close to 0 ) have also been evaluated for PDT [63,64]. Li et al. [63] developed $\mathrm{W}_{2} \mathrm{C}$ nanoparticles, synthetized the calcination at $800{ }^{\circ} \mathrm{C}$ of an organic-inorganic hybrid structure consisting in $\mathrm{WO}_{4}{ }^{-}$subunits coordinated to polydopamine nanoparticles. Their resulting metallic-like 
behavior could achieve photocatalysis under $1064 \mathrm{~nm}$ irradiation light due to the creation of $\mathrm{e}^{-} / \mathrm{h}^{+}$pairs via interband transitions [67]. The photo-generated charges could produce - $\mathrm{OH}$ and ${ }^{1} \mathrm{O}_{2}$ species, detected by electron paramagnetic resonance (EPR) (Figure 3c). ROS were enough to provoke tumor ablation without injuring surrounding organs. Although engineering low $E_{g}$ photocatalysts entails a precise control of its band structure, size and morphology, the nanosystems developed so far have shown encouraging PDT outcomes results to keep on evaluating NIR-responsive photocatalysts for cancer treatment.
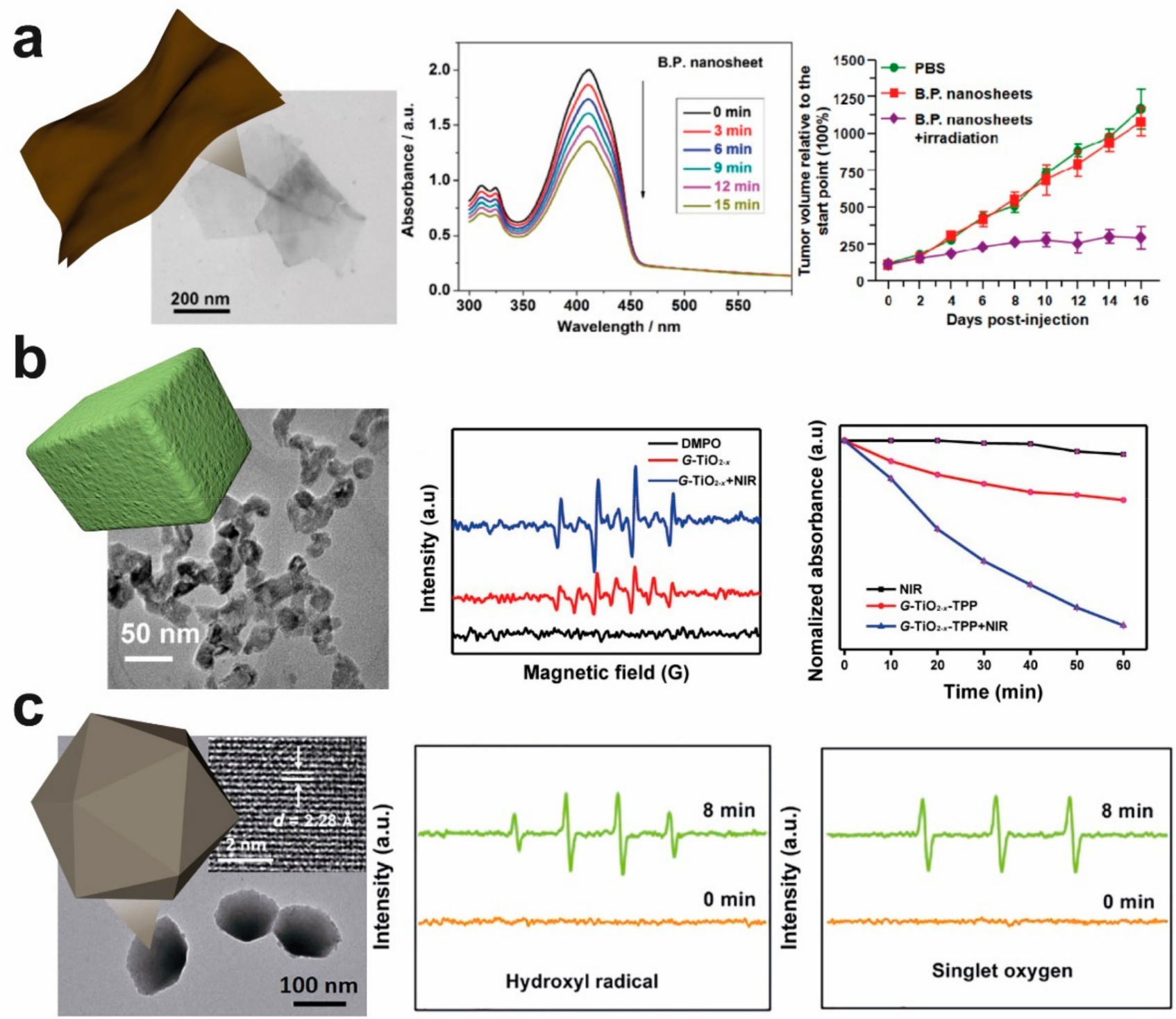

Figure 3. Different low $E_{g}$ photocatalysts developed for PDT. (a) TEM image of BP nanosheets and evolution of the catalytic conversion of $\mathrm{O}_{2}$ into ${ }^{1} \mathrm{O}_{2}$ under $650 \mathrm{~nm}$ light irradiation. Applying those conditions reduced considerably the tumor size in Balb/c mice. Reprinted with permission from [47]. Copyright (C) 2015 American Chemical Society; (b) TEM image of Green- $\mathrm{TiO}_{2}\left(\mathrm{G}-\mathrm{TiO}_{2}\right)$ applied for PDT. EPR experiment demonstrating the capability of $\mathrm{G}-\mathrm{TiO}_{2}$ of generating $\mathrm{OH}$ radicals in the presence of $980 \mathrm{~nm}$ irradiation. Photocatalytic degradation of 1,3-diphenylisobenzofuran in $\mathrm{G}^{-\mathrm{TiO}_{2}} / 980 \mathrm{~nm}$ system indicating ROS generation. Reprinted with permission from [54]. Copyright (C Ivyspring International Publisher; (c) TEM image of $\mathrm{W}_{2} \mathrm{C}$ nanoparticles together with EPR spectra of $\bullet \mathrm{OH}$ and ${ }^{1} \mathrm{O}_{2}$ species after irradiation with $1064 \mathrm{~nm}$, confirming the photoactivity of $\mathrm{W}_{2} \mathrm{C}$ nanoparticles towards ROS production. Reprinted with permission from [63]. Copyright $($ Tsinghua University Press and Springer-Verlag GmbH Germany, part of Springer Nature 2018. 


\subsection{Carbon-Based Photocatalysts}

Engineering suitable $\mathrm{E}_{\mathrm{g}}$ has been also successfully explored for carbon-based nanomaterials [21,51]. Different carbon nanostructured have been engineered to achieve the photocsatalytic process inside tumor cells, including single-walled carbon nanotubes (SWCN) [56], fullerenes $\left(\mathrm{C}_{60}\right)$ [58], graphene oxide [57] or carbon dots [68,69]. $\mathrm{Xu}$ and co-workers developed a methodology to promote NIR-absorption in $\mathrm{C}_{3} \mathrm{~N}_{4}$ nanoparticles consisting in intercalating $\mathrm{K}$ within the $\mathrm{C}_{3} \mathrm{~N}_{4}$ structure [51]. This chemical modification altered the position of $\mathrm{CB}$ of $\mathrm{C}_{3} \mathrm{~N}_{4}$ from $+1.71 \mathrm{~V}$ to $+0.71 \mathrm{~V}$, achieving an $\mathrm{E}_{\mathrm{g}}$ of $1.71 \mathrm{eV}$, suitable for photo activation under biocompatible irradiation. Although most developed photocatalysts for PDT focus on the ROS production from photogenerated $\mathrm{e}^{-} / \mathrm{h}^{+}$pairs some works have shown the potential of these $\mathrm{h}^{+}$to subsequently oxidize key tumor molecules such as GSH. Thus, catalytic GSH depletion is considered a new horizon in cancer therapy research [22]. VB position K-doped- $\mathrm{C}_{3} \mathrm{~N}_{4}$ photocatalyst $(0.71 \mathrm{~V})$ allowed the $\mathrm{GSH}$ oxidation reaction into GSSG $\left(0.32 \mathrm{~V}\right.$ [51]) while $\mathrm{CB}$ position $(-1.0 \mathrm{~V})$ supported $\mathrm{H}_{2}$ evolution from $\mathrm{H}^{+}$reaction. The majority of classic photocatalysts usually work under ultraviolet-visible (UV-vis) irradiation, which does not penetrate skin and consequently, does not reach tumor sites [3]. Another strategy to mainly activate carbon-photocatalysts inside a tumor consist in the combination of upconverting nanoparticles (UCNP) and photoactive nanostructures. UCNP are able to absorb two photons with low energy (and thus, with large tissue penetrability) and convert them into a more energetic photon, suitable to interact with the VB of a semiconductor [70] and carry out photocatalytic process. g- $\mathrm{C}_{3} \mathrm{~N}_{4}$ is a widely used efficient photocatalyst applied in water splitting, organic transformations or environmental remediation [71]. Its application in PDT has been reported with different morphologies (g- $\mathrm{C}_{3} \mathrm{~N}_{4}$ quantum dots [72,73] or g- $\mathrm{C}_{3} \mathrm{~N}_{4}$ nanosheets [74]) in combination with UCNP, as $\mathrm{E}_{\mathrm{g}}$ of $\mathrm{g}-\mathrm{C}_{3} \mathrm{~N}_{4}$ value is $2.7 \mathrm{eV}$ (i.e., $<475 \mathrm{~nm}$ ).

These materials also tackled the oxygen scarcity issue associated to the TME [75] Photogenerated $\mathrm{e}^{-}$are able to interact with $\mathrm{O}_{2}$ to form ${ }^{1} \mathrm{O}_{2}$ or $\bullet \mathrm{O}_{2}{ }^{-}$, and consequently the limited supply of $\mathrm{O}_{2}$ entails a loss of PDT efficiency. Chen et al. [21] developed $\mathrm{C}_{5} \mathrm{~N}_{2}$ nanoparticles with a characteristic $\mathrm{VB}$ with a potential of $2.06 \mathrm{~V}$ enough to oxidize $\mathrm{H}_{2} \mathrm{O}$ into $\mathrm{O}_{2}$ and overcome the tumoral hypoxia, while generating ${ }^{1} \mathrm{O}_{2}$ from the produced $\mathrm{O}_{2}$. The major advantage of this system lies in its ability to correct photocatalytic activity despite the hypoxic environment (Figure 4a) inherent to tumor cells. CDs have emerged as outstanding materials to perform diagnosis and therapy as single freestanding platforms [68]. The synthesis of CDs comprises the calcination of an organic molecule [59], generally containing nitrogen to provide the $\mathrm{CD}$ of an expanded energy level to provide an enhanced photocatalytic response towards the visible-NIR ranges [76]. In this way, the synthetic versatility and chemical affinity of $\mathrm{CDs}$ favors the integration and enhanced interaction with PSs to provide an efficient ${ }^{1} \mathrm{O}_{2}$ generation. Likewise, CDs are also able to increase the solubility and stability of PSs, as pointed out by Xie et al. [60]. CDs may also perform PDT on their own [59,69] (Figure 4b) positioning them as promising theragnostic materials. Finally, another smart approach to overcome PSs limitations is the design of metal organic frameworks (MOFs) with PSs integrated (Figure 4c) within their reticular structure $[61,62,77]$. The catalytic activity of these MOFs yields the same product as in the case of PSs (i.e., ${ }^{1} \mathrm{O}_{2}$ ), but with enhanced stability. 
a

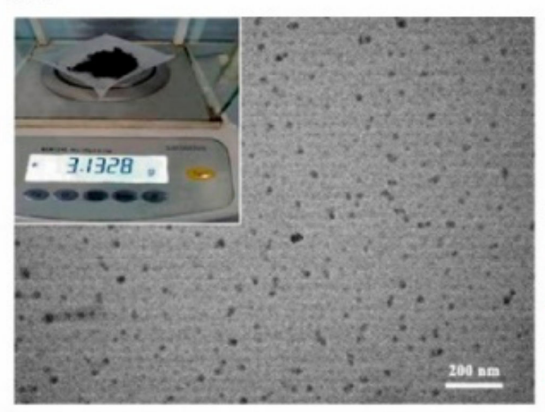

b

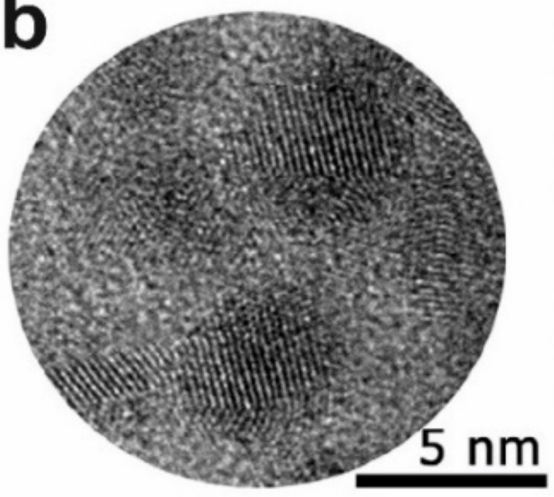

PBS
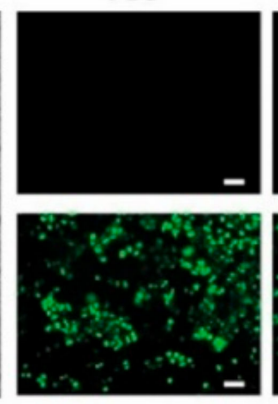

$\mathrm{C}_{5} \mathrm{~N}_{2}+650$
650
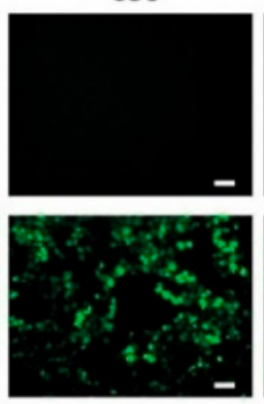

$\mathrm{C}_{5} \mathrm{~N}_{2}+650$, hypoxia
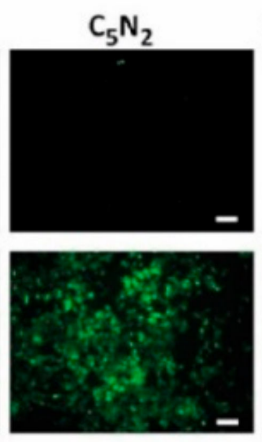

Ce6 +650
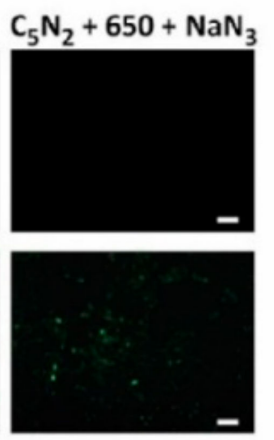

Ce6 +650 , hypoxia
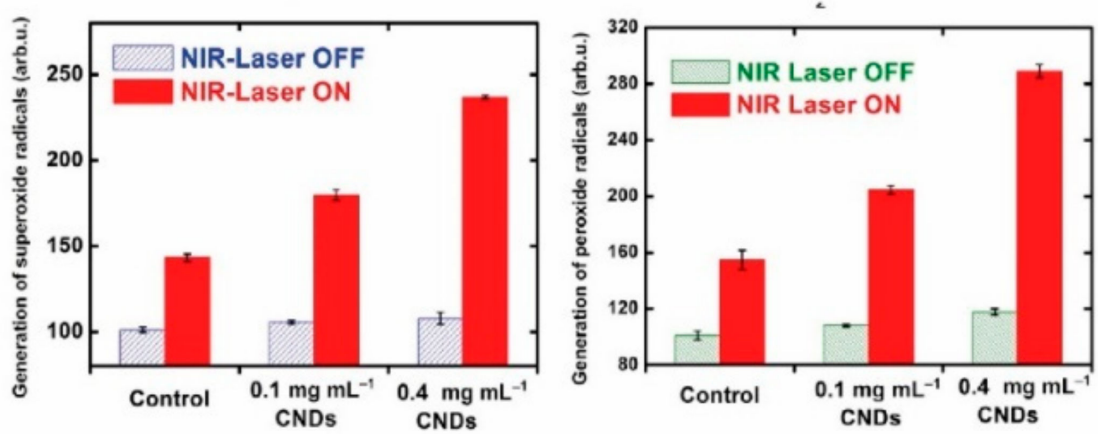

NDs
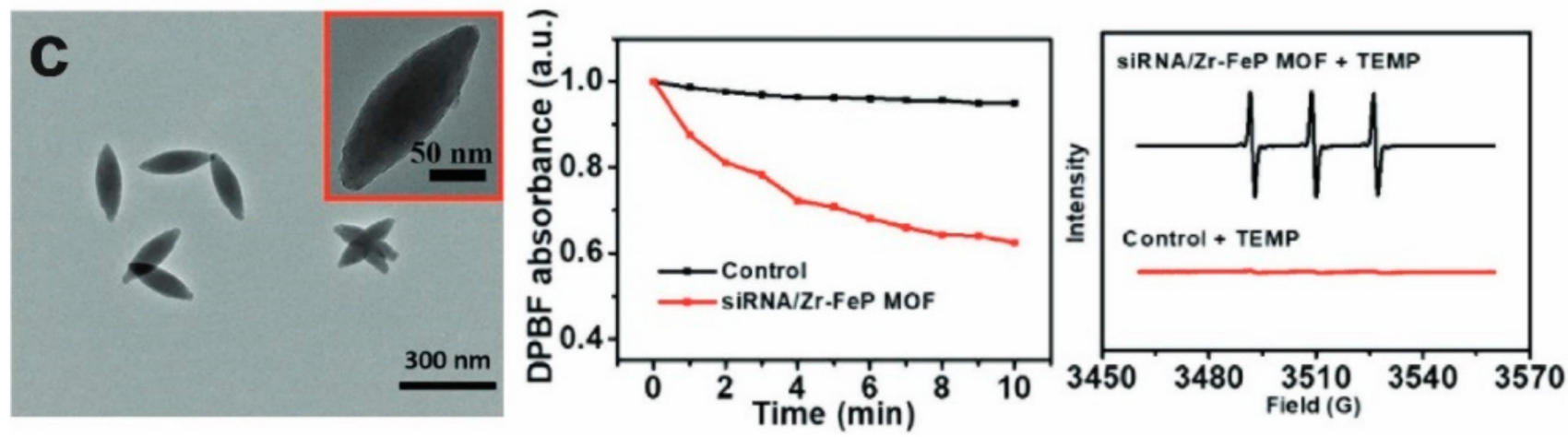

Figure 4. Selection of carbon-based photocatalysts developed for PDT. (a) TEM image of K-doped $\mathrm{C}_{3} \mathrm{~N}_{4}$ nanoparticles applied for PDT. In vitro experiments demonstrate the $\mathrm{K}-\mathrm{C}_{3} \mathrm{~N}_{4}$ capability of generate $\mathrm{O}_{2}$ and ${ }^{1} \mathrm{O}_{2}$ simultaneously under $650 \mathrm{~nm}$ light irradiation. Reprinted with permission from [21]. Copyright (C 2021 Wiley-VCH GmbH; (b) TEM image of N-doped carbon dots and their in vitro photogeneration of peroxide and superoxide species under NIR irradiation. Reprinted with permission from [59]. Copyright (C) 2019 Wiley-VCHVerlag GmbH\&Co. KGaA, Weinheim; (c) TEM image of zirconium-ferriporphyrin metal organic framework (Zr-FeP MOF). Photocatalytic performance of $\mathrm{Zr}$-FeP MOF generating ${ }^{1} \mathrm{O}_{2}$ demonstrated by DPBF assay and EPR spectroscopy. Reprinted with permission from [63]. Copyright (C) 2018 WILEY-VCH Verlag GmbH \& Co. KGaA, Weinheim.

\section{Noble Metal-Based Photocatalysts for Cancer Therapy}

3.1. Conjugation of PSs with Noble-Metal Nanoparticles versus Direct $\mathrm{O}_{2}$ Photoactivation on the Metal Surfaces for PDT

Until very recently, the use of metallic nanoparticles in PDT for cancer therapy had been strictly restricted to PS-bioconjugated metal nanohybrids. Different metal nanoparticles (Au, Pd, Pt) have been bioconjugated with organic PSs such as Chlorine e6 (Ce6) or Indocyanine Green (ICG). Hybrid systems take advantage of physical, optical and cat- 
alytic properties of metal NPs to either improve the efficacy of PDT or promote synergistic co-therapies. $\mathrm{Pt}$ and $\mathrm{Pd}$ nanoparticles are able to catalyze $\mathrm{H}_{2} \mathrm{O}_{2}$ decomposition to form $\mathrm{O}_{2}$, alleviating tumor hypoxia and enhancing better results in $\mathrm{O}_{2}$-dependent PDT [78,79]. Moreover, Au-based materials have been also used to perform two in one PTT/PDT [80].

One of the first examples of metal nanoparticles use for ${ }^{1} \mathrm{O}_{2}$ generation was reported by Kotiaho et al. [81]. Taking advantage of classical organic PS molecules to enhance ${ }^{1} \mathrm{O}_{2}$ generation, Au NPs were bioconjugated with thiolated phthalocyanines. It was been demonstrated how phthalocyanine-functionalized Au NPs successfully photo-induced charge and energy transfer between the metal surface and the organic bonded macrocycle. They concluded how a selective excitation of the gold cores in the pump-probe experiment results in an energy transfer from the gold nanoparticles to the attached phthalocyanines in $\sim 2.4$ ps. Moreover, photoexcitation of the phthalocyanines attached to the functionalized nanoparticles led to an electron transfer to the gold core in $\sim 3.0 \mathrm{ps}$. Therefore, the energydonating ability of the gold nanoparticles can be used to extend the absorption range of phthalocyanine, and, at the same time, charge separation between phthalocyanines and gold nanoparticles is achieved (Figure 5).

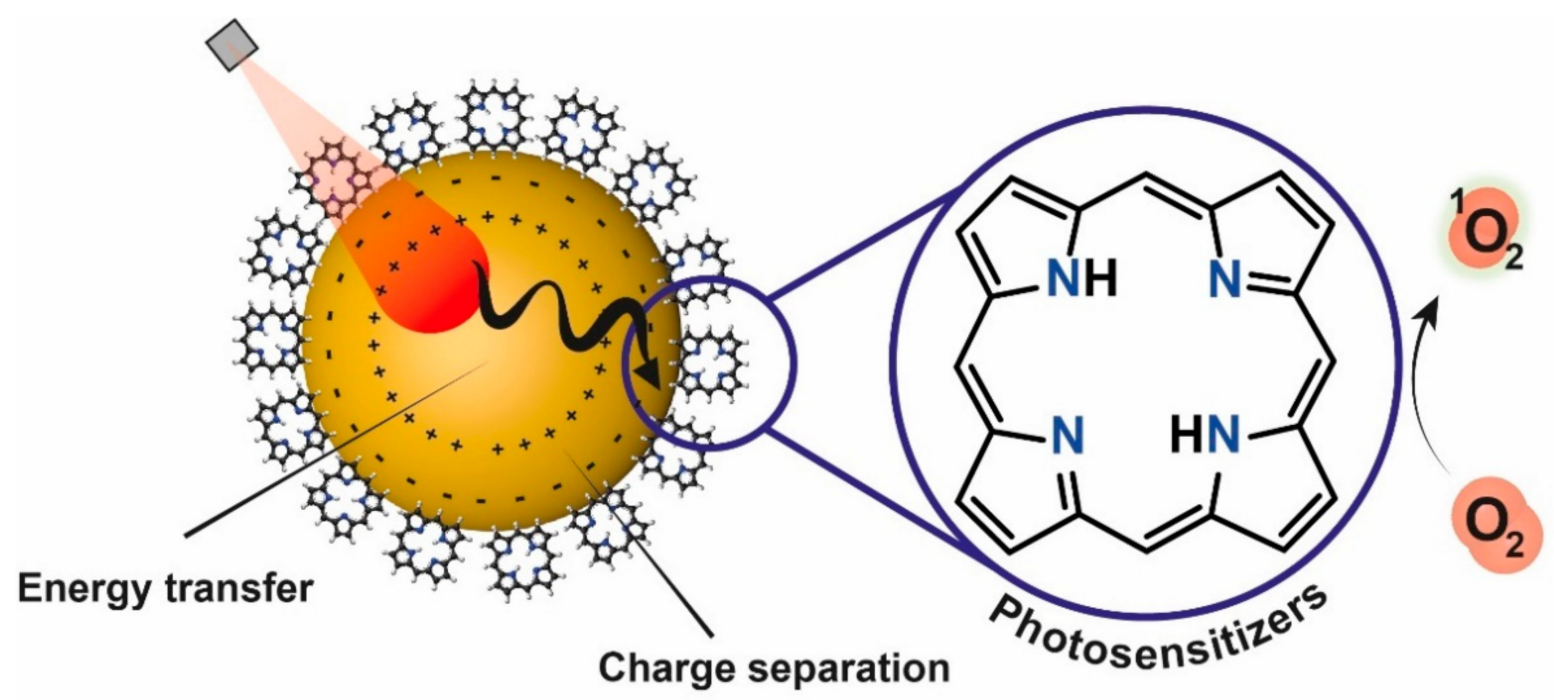

Figure 5. Synergy between phthalocyanines conjugated to noble-metal nanoparticles responsive to biocompatible irradiation. The excitation of $\mathrm{e}^{-}$own to noble-metal nanoparticles provoke its transference to the organic molecule bonded to the nanostructure surface to transform dissolved $\mathrm{O}_{2}$ into reactive ${ }^{1} \mathrm{O}_{2}$. Moreover, this electronic transference boosts a charge separation between the phthalocyanine and the nanoparticle to enhance the photocatalytic process [81].

\subsection{Influence of the Crystalline Facets Exposed to $\mathrm{O}_{2}$}

Less attention has been traditionally paid to selectively promote a photo-induced charge and energy transfer directly between the metal surface and $\mathrm{O}_{2}$. Raviraj et al. [43] demonstrated that metallic nanoparticles $(\mathrm{Au}, \mathrm{Ag}, \mathrm{Pt})$ could selectively generate ${ }^{1} \mathrm{O}_{2}$ species without organic sensitizer requirement under irradiation (100 W high-pressure $\mathrm{Hg}$ lamp for 2 min). Light-induced $\mathrm{O}_{2}$ activation takes place after an effective chemisorption onto the surface of the metal nanoparticle. However, $\mathrm{O}_{2}$ tend to dissociate on the catalytic surface of metals and only keeps the molecular form in the presence of specific crystalline facets of the metal nanocrystals (Figure 6a) [82]. For instance, (111) orientations in Ag nanocrystals preferentially chemisorb molecular $\mathrm{O}_{2}$. In contrast, (100) and (110) planes are prone to accommodate the dissociated atomic $\mathrm{O}$ species. Only molecular oxygen can be further activated to generate ${ }^{1} \mathrm{O}_{2}[43,82]$. Thus, the irradiation wavelength, the type of metal used, morphology and the type of facets exposed are fundamental parameters to evaluate and predict the suitability and potential of metal nanoparticles as PDT agents. 

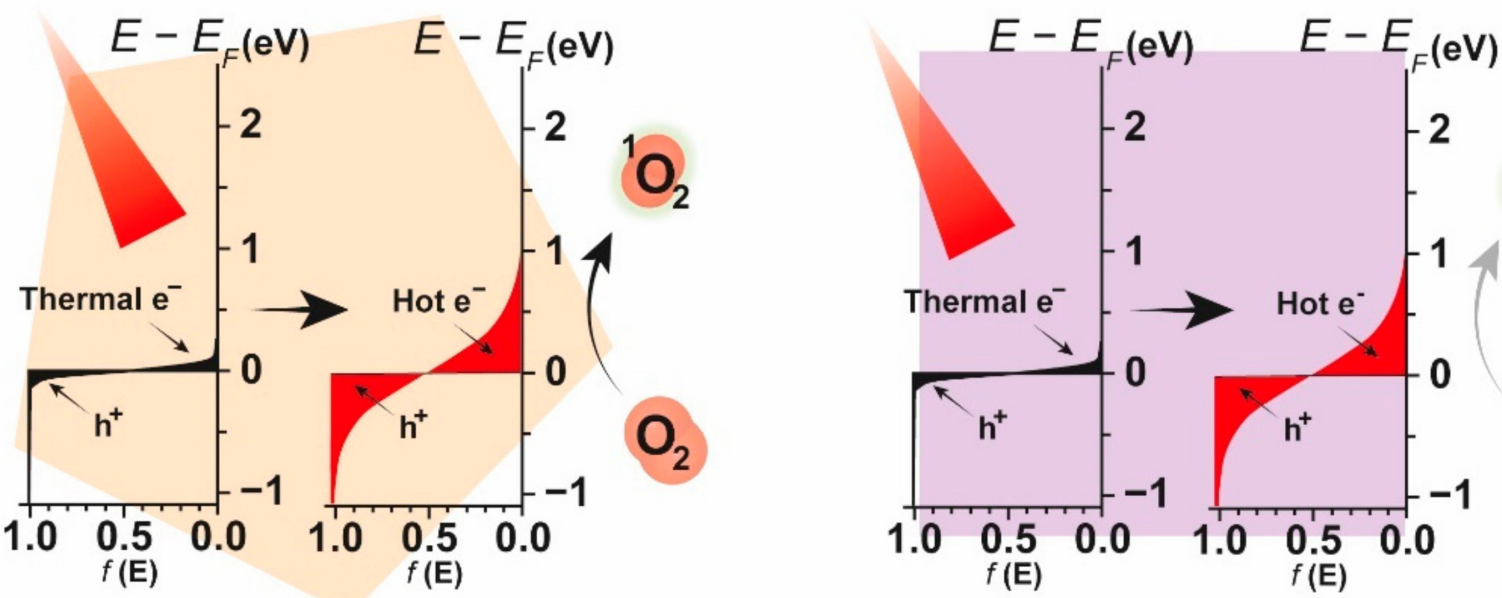

Fundamental State

b
Continuous laser

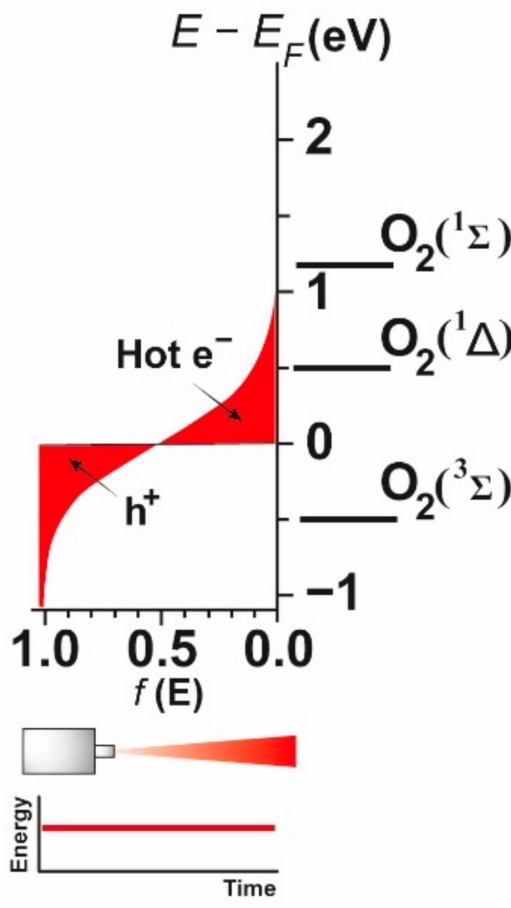

Pulsed Laser

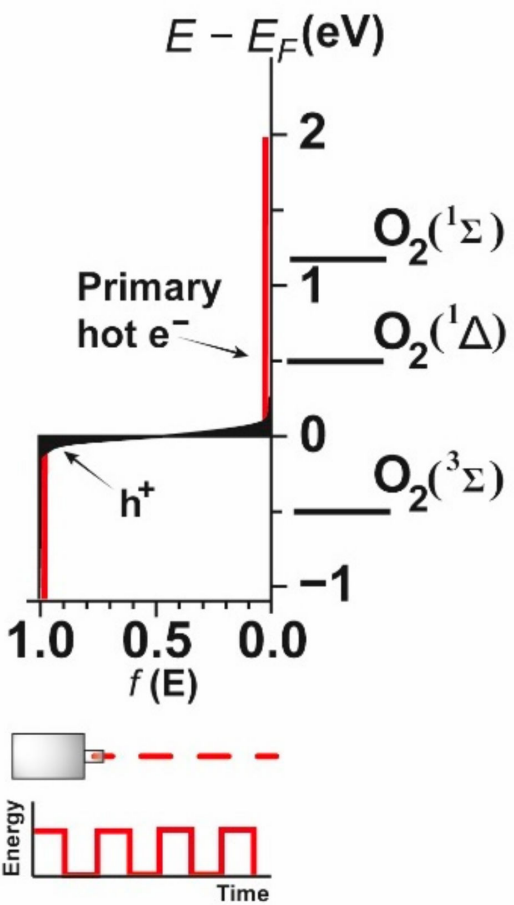

Figure 6. (a) Crystalline-facet dependence in singlet oxygen generation. $\mathrm{O}_{2}$ stabilization in certain surface facet promote an efficient energy transfer between metal crystals and previous chemisorb $\mathrm{O}_{2}$; (b) Schematic illustration of metal-based photo-excitation under visible and NIR excitation wavelengths. Non-irradiated condition with excited thermal electrons, light irradiation and its subsequent response to generate highly energetic primary hot electron/holes followed by electron/holes equilibrium stabilization as a function of the type of laser used.

\subsection{Influence of the Type of Laser Irradiation Source}

Pasparakis et al. studied the generation of ${ }^{1} \mathrm{O}_{2}$ in culture media when it was incubated with gold nanoparticles $(40 \mathrm{~nm})$ under laser irradiation $\left(\lambda_{\mathrm{exc}}=532 \mathrm{~nm}\right)$. To investigate the PDT induced cell death mechanism, they performed analogous studies in the presence of ${ }^{1} \mathrm{O}_{2}$ scavengers such as ascorbic acid (AA) or 1,3-diphenylisobenzofuran (DPBF). When 
AA or DPBF were co-incubated, cell death was dramatically reduced, thereby indicating that in their case, Au NPs were inducing cell death using ${ }^{1} \mathrm{O}_{2}$ as the dominating and more abundant ROS. Moreover, they studied the influence of the laser sources and tested continuous wave $(\mathrm{CW})\left(50 \mathrm{~mW} / \mathrm{cm}^{2}\right.$ for $\left.20 \mathrm{~s}\right)$ and pulsed laser irradiation $\left(30 \mathrm{~mJ} / \mathrm{cm}^{2} \cdot\right.$ pulse, 33 pulses with $10 \mathrm{~Hz}$ repetition rate) modes. Their results showed a higher fraction of ${ }^{1} \mathrm{O}_{2}$ when pulsed laser irradiation was applied [83]. Variations in cell viability were attributed to differences in the laser-induced activation pathways. CW irradiation induced an activation mechanism enabled by the interaction of plasmons and hot electrons with molecular $\mathrm{O}_{2}$, and an indirect photothermal pathway.

The pulsed laser source may also induce extreme heat leading to a potential particle fragmentation and increased thermionic electron emission (Figure 6b). Chadwick et al. [84] studied the influence of the variation of metal nanoparticle size to generate singlet oxygen under laser irradiation ( $\lambda_{\text {exc }}=532 \mathrm{~nm}$ either with CW or pulsed laser irradiation). They evaluated citrate capped gold nanoparticles of 15 and $46 \mathrm{~nm}$ and they found a greater ability of the larger Au NPs to form singlet oxygen species. They attributed a higher capacity of bigger gold nanoparticles to generate more hot electrons compared with small ones. Moreover, they carried out a systematic comparison between both, CW and pulsed laser irradiation. Pulsed laser irradiation acted via the equilibrated hot electrons, reaching temperatures of several thousand degrees during each laser pulse. $\mathrm{CW}$ can act only via the directly excited primary hot electrons, losing energy by electron-electron equilibration and consequently minimizing ${ }^{1} \mathrm{O}_{2}$ generation under analogous conditions (Figure 6b).

\subsection{Influence of the Shape, Morphology and Aggregation State of the Nanoparticles}

The influence of shape and morphology was systematically investigated by Zhao et al. [85]. They carried out experiments irradiating Au nanorods (Au NRs) with different aspect ratios with a two-photon laser source ( $808 \mathrm{~nm}$ with an energy density of $3.0 \mathrm{~W} \mathrm{~cm}^{-2}$ ). $\mathrm{Au}$ NRs (maximum absorbance band at 765, 808 and $835 \mathrm{~nm}$ ) were compared with other representative organic singlet oxygen sensitizers such as ICG or Rose Bengal (RB). As a result, ${ }^{1} \mathrm{O}_{2}$ generation efficiencies were enhanced in the presence of $\mathrm{Au}$ NRs under two-photon laser irradiation. Moreover, Au NRs with a maximum absorbance at $808 \mathrm{~nm}$ exhibited a better performance towards ${ }^{1} \mathrm{O}_{2}$ generation than those with maxima absorbance bands centered at 765 and $835 \mathrm{~nm}$. The high efficiency of Au NRs for PDT with two-photon laser irradiation was not observed with a one-photon excitation source.

Jiang et al. also evaluated the influence of the aggregation state of Au NPs and Au NRs to promote ${ }^{1} \mathrm{O}_{2}$ generation [86]. They reported a dramatically enhanced ROS generation when both nanospheres and nanorods were aggregated. They realized that aggregated spherical Au NPs and short Au NRs enhanced ROS generation. In contrast, aggregation in longer Au NRs did not promote a significant increment in ROS generation values.

It has been shown how aggregated Au NPs expand their absorbance toward higher wavelength values than their isolated counterparts [87]. Jiang et al. [86]. performed singlet oxygen generation experiments under $800 \mathrm{~nm}$ laser irradiation conditions (beam area $=$ $0.3 \mathrm{~cm}^{2}$, pulse duration of $60 \mathrm{fs}$ and repetition rate of $1 \mathrm{kHz}$ and energy power density of $3.0 \mathrm{Wcm}^{-2}$ ). LPR of Au NPs and short Au NRs are located around 500 and $700 \mathrm{~nm}$ respectively. However, LPR of longer Au NRs is located around $800 \mathrm{~nm}$. Cysteine addition tends to aggregate gold nanostructures and shift the maximum plasmon peak of Au NPs and short Au NRs from lower wavelength to around $800 \mathrm{~nm}$ wavelength, generating gold-based structures with a maximum peak around the irradiation wavelength used.

Au nanostructures in general, tend to aggregate inside cells. There are several reasons why Au NPs can aggregate. Albanese et al. [88] discussed the influence of $\mathrm{NaCl}$ to neutralize the stabilizing electrostatic forces on the citrate-capped Au NPs and cause the van der Waals forces to drive aggregation. Yang et al. [89] also evaluated intracellular Au NPs aggregation and their potential application in PDT. They synthetized Au NPs with different surface charge and performed a co-incubation of both positive and negative gold nanoparticles to 
promote a further intracellular aggregation. Gold nanoaggregates performed better results in terms of ${ }^{1} \mathrm{O}_{2}$ generation compared with non-aggregated gold nanoparticles.

Vankaya et al. [90] evaluated the one-photon laser irradiation of Au NRs and its photocatalytic oxygen activation for ${ }^{1} \mathrm{O}_{2}$ generation. They performed in vitro and in vivo experiments using polymer coated Au NRs to enhance PTT and PDT. They tested irradiation wavelengths in the visible $(550 \mathrm{~nm})$ and NIR $(940 \mathrm{~nm})$ windows to significantly reduce HeLa cell viability. They confirmed that the irradiation at $550 \mathrm{~nm}$ induced killing of HeLa cells by a photothermal effect. HSP 70 is considered the most sensitive biological indicator for thermal shocking stress. Upon $550 \mathrm{~nm}$ laser irradiation, HSP 70 levels were considerable higher than blank experiments, as well as $940 \mathrm{~nm}$ laser irradiation experiments. Moreover, experiments performed at $4{ }^{\circ} \mathrm{C}$ confirmed photothermal effect of Au NRs by significantly suppressed HSP 70 overproduction. On the other hand, death mechanism of HeLa cells upon $940 \mathrm{~nm}$ laser irradiation mainly turned on a ROS-mediated PDT. Experiments carried out under $940 \mathrm{~nm}$ laser irradiation at $37^{\circ} \mathrm{C}$ and $4{ }^{\circ} \mathrm{C}$ showed no significant increase of HSP 70. Likewise, experiments performed at reduced temperature were able to generate a major fraction of ROS in comparison with the analogous experiments at $37^{\circ} \mathrm{C}$. To confirm ROS-mediated cell death mechanism, cells were pretreated with $\mathrm{NaN}_{3}$, a well-known ROS inhibitor, that confirmed the lower ROS production levels at both reaction temperatures. Furthermore, in vivo studies were also performed under $780 \mathrm{~nm}$ and $915 \mathrm{~nm}$ laser irradiation wavelength with identical outcome. Enhanced ROS generation were obtained under $915 \mathrm{~nm}$ laser irradiation, thereby indicating the need to select the proper NIR irradiation source to match the coupling with the nanometals and maximize the penetration depth.

Vijayaraghavan et al. [91] also explored a different nanometallic photocatalyst design based on multi-branched Au nanourchins (Au NUs) for PTT and PDT activated in the first and second biological window (Figure $7 \mathrm{a}-\mathrm{c}$ ). They synthetized a polymer-coated Au-based multibranched nanoarchitecture with expanded NIR absorption towards the first and second window. Analogous studies were analyzed at $4{ }^{\circ} \mathrm{C}$ and $37{ }^{\circ} \mathrm{C}$ and in the presence/absence of the $\mathrm{NaN}_{3}$ scavenger and similar results were obtained (Figure $7 \mathrm{~d}$ ). Moreover, taking advantage of its expanded absorption properties, Au NUs were evaluated to selectively perform PTT/PDT at different wavelengths. ${ }^{1} \mathrm{O}_{2}$ generation for Au NUs was evaluated under $550 \mathrm{~nm}$ and $808 \mathrm{~nm}\left(\mathrm{CW}\right.$ lasers at $130 \mathrm{~mW} / \mathrm{cm}^{2}$ power intensity for $10 \mathrm{~min}$ ) laser irradiation wavelengths and no significant results were obtained. In contrast, $915 \mathrm{~nm}$ and $1064 \mathrm{~nm}$ NIR sources selectively enhanced ${ }^{1} \mathrm{O}_{2}$ generation with the Au NUs (Figure 7e,f). The authors attributed the selective tendency to either PTT or PDT to the unprecedented architecture of the Au NUs. It has been shown how Au NRs are active when they were irradiated under first biological window $(915 \mathrm{~nm})$ but not when second biological window was used $(1064 \mathrm{~nm})$. However, Au NUs showed a remarkable activity in both the first and second biological windows, respectively [91]. To further clarifying the influence of wavelength used and its PDT response, fluorescence experiments were performed and different excitation wavelength-dependent response were monitored. The quantum yields for sensitization of singlet oxygen by Au NUs were considerable higher than obtained for conventional organic photosenitizer or UCNPs sensitized organic photosensitizer under NIR light irradiation [92]. 

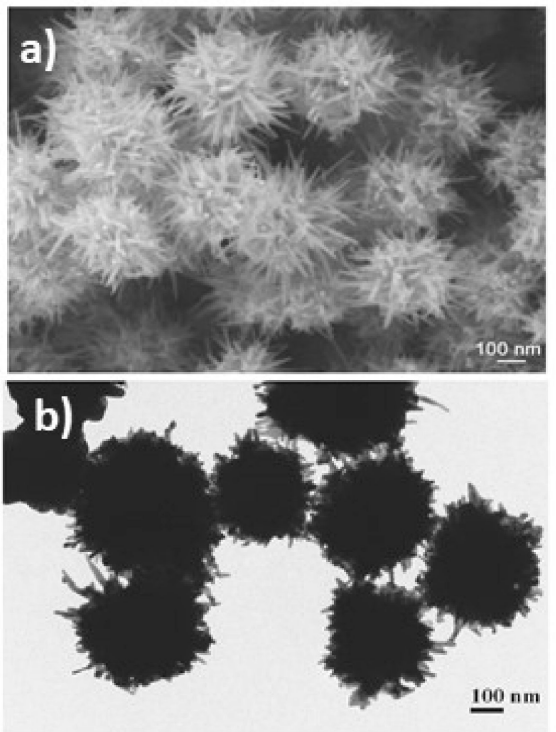

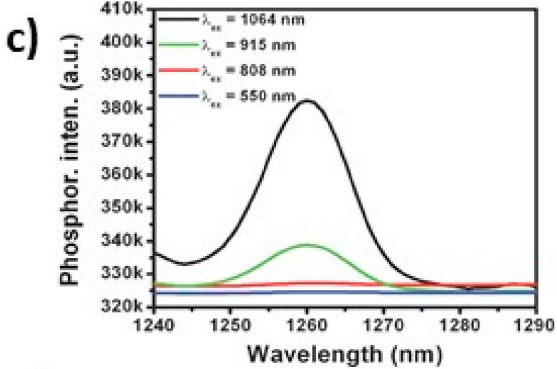

d)

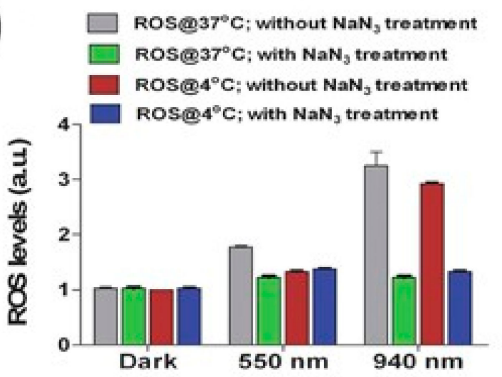

e)

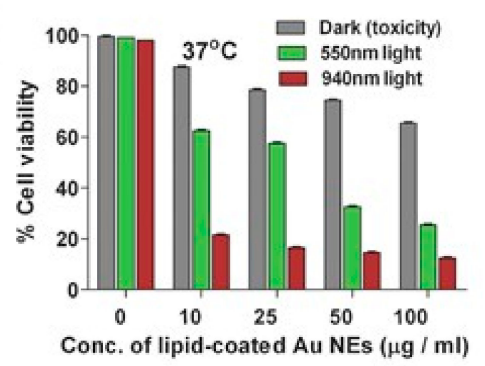

f)

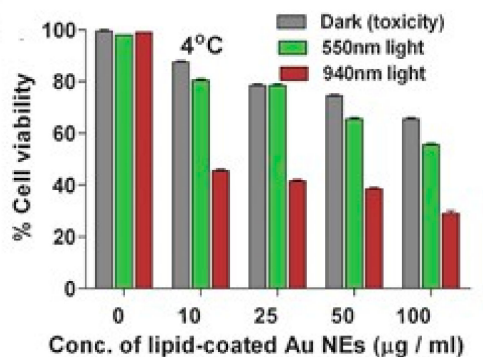

Figure 7. Several examples of gold-based nanoarchitectures with light-induced features to promote PDT and selectively enhance in vitro and in vivo cancer therapy. (a) Scanning electron microscope (SEM) and (b) TEM images for Au NUs; (c) ${ }^{1} \mathrm{O}_{2}$ phosphorescence emission spectra sensitized by lipid-coated Au NUs at 550, 808, 915, 1064 nm excitation wavelengths; (d) In vitro ROS generation monitored by the mean DCF fluorescence using flow cytometry for lipid-coated Au NUs internalized HeLa cells followed by photo-irradiation with and without $\mathrm{NaN}_{3}$ pretreatment, (e) cell viabilities of lipid-coated Au NUs internalized HeLa cells under dark and photoirradiation at $37^{\circ} \mathrm{C}$ and (f) $4{ }^{\circ} \mathrm{C}$. Reprinted with permission from [91]. Copyright ( 2014 WILEY-VCH Verlag GmbH \& Co. KGaA, Weinheim.

\subsection{PDT with Other Noble Metal Nanocatalysts beyond Gold}

Although less exploited, it is also worth mentioning that other noble metals beyond $\mathrm{Au}$ have been successfully reported in the recent literature as alternative photocatalysts able to perform PDT or another co-adjuvant therapy treatment (Table 2, vide infra). Pd and $\mathrm{Pt}$ nanoparticles have been widely used to selectively bioconjugate organic photosensitizers and perform PDT [35,38]. However, there are fewer examples where these metals have been used in the organic PSs to efficiently enhance PDT for cancer treatment. Li et al. [93] developed novel biodegradable holey palladium nanosheets (Pd NSs) with intrinsic photocatalytic and hypoxia-resistant capacities (Figure 8). For the first time, they fabricated Pd nanosheets with an anisotropic oxidative etching strategy which introduces one-dimensional nanoholes with active (100) facets on the hole walls. ${ }^{1} \mathrm{O}_{2}$ photocatalytic activity was tested by EPR. Hypoxia-resistant capacities were evaluated by adding $\mathrm{H}_{2} \mathrm{O}_{2}$ and monitoring $\mathrm{O}_{2}$ generation. ${ }^{1} \mathrm{O}_{2}$ generation were performed under $808 \mathrm{~nm}$ laser irradiation $\left(1 \mathrm{~W} \mathrm{~cm}^{-2}\right)$ and modified Pd nanosheets (H-PdNSs) showed better yields compared with analogous non modified PdNSs. Moreover, $\mathrm{H}_{2} \mathrm{O}_{2}$ addition promoted higher efficiency for ${ }^{1} \mathrm{O}_{2}$ formation compared with control experiments without $\mathrm{H}_{2} \mathrm{O}_{2}$ addition. It was explained how H-PdNSs have new exposed planes (100) and how $\mathrm{O}_{2}$ is more favorable to chemisorb in (100) planes compared with other more relevant planes in non-modified PdNSs. 4T1 cells were incubated with H-PdNSs and irradiated with NIR (808 nm laser with a power density of $1 \mathrm{~W} \mathrm{~cm}^{-2}$ for $3 \mathrm{~min}$ ) showed greater therapeutic efficacy than non-modified Pd NSs, which could be attributed to the outstanding PDT performance. In order to investigate the hypoxia modulation ability of $\mathrm{H}-\mathrm{Pd} \mathrm{NSs}$ in vitro, $\mathrm{H}-\mathrm{Pd} \mathrm{NSs}$ was tested under both normoxic and hypoxic conditions. The results showed that the cancer cell killing efficiency of H-Pd NSs showed no obvious differences between normoxia and hypoxia, meanwhile, PdNSs showed higher differences between both normoxia and hypoxia experiments. 


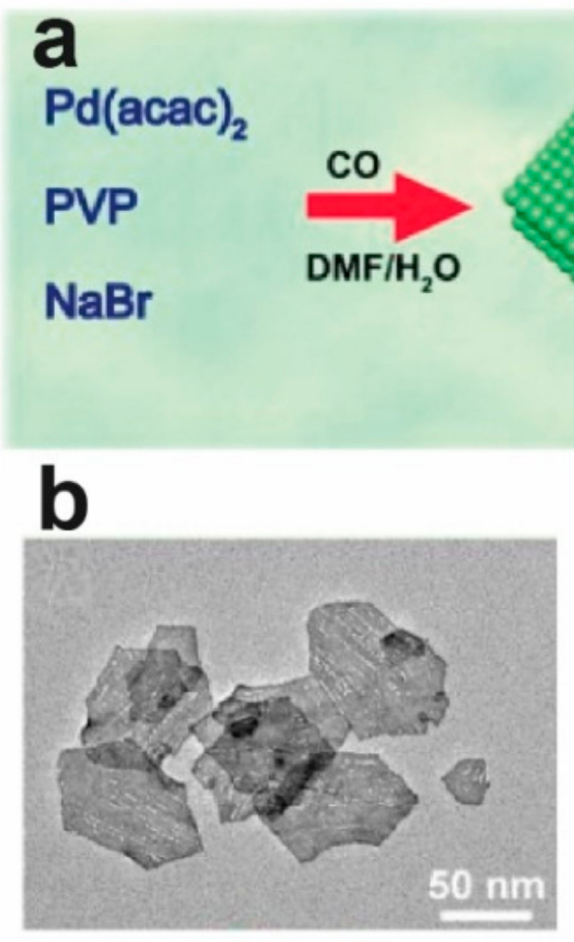

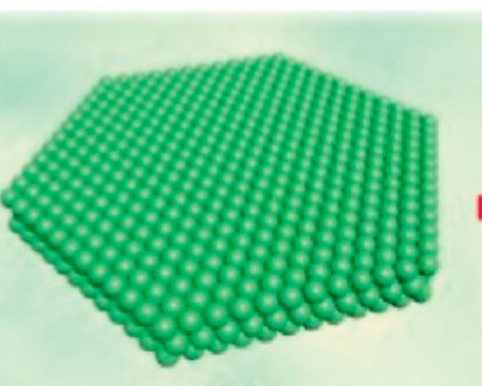

Pd NSs

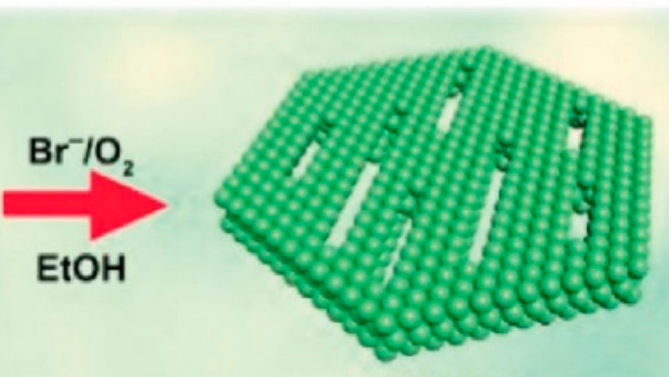

H-Pd NSs
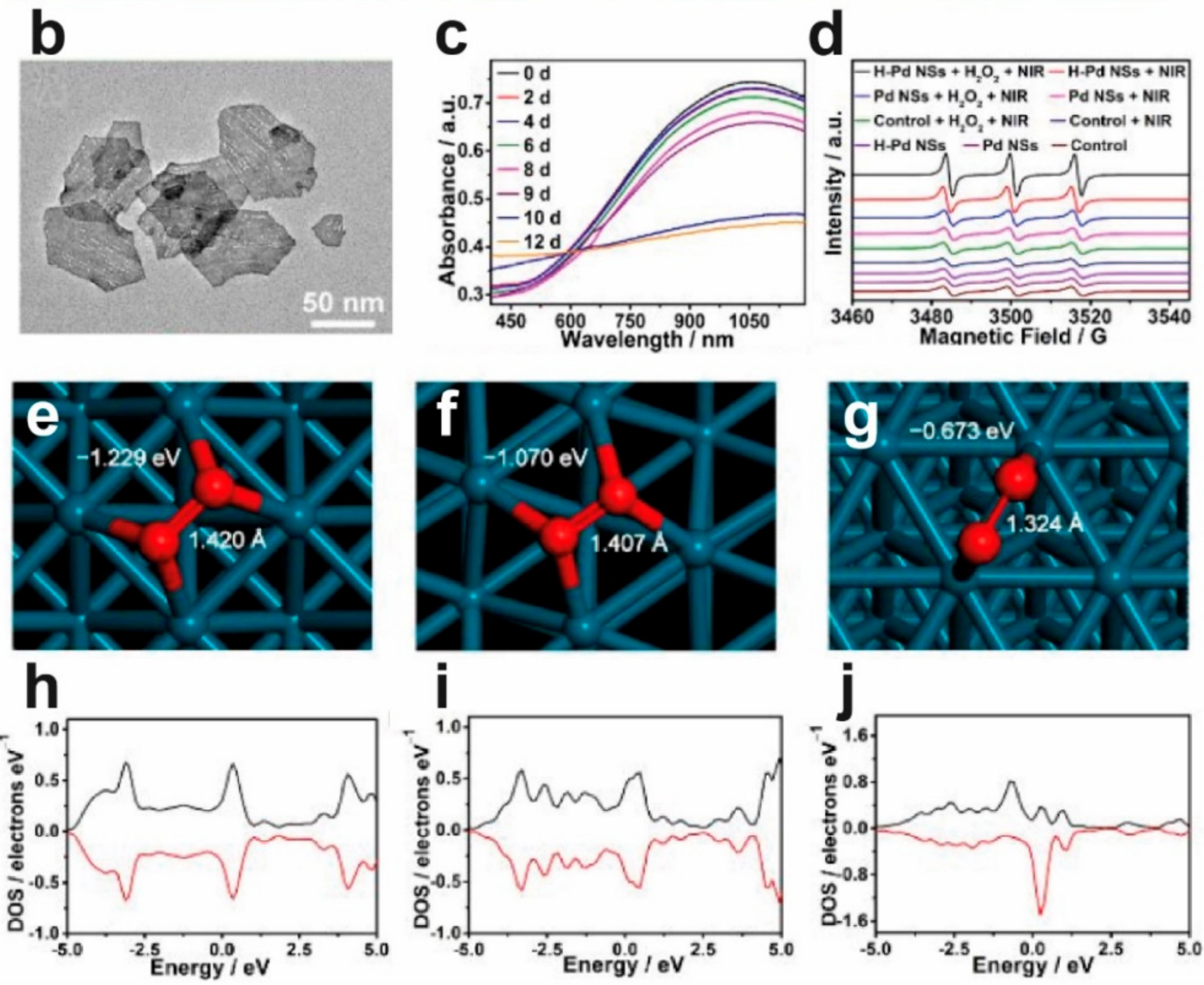

Figure 8. (a) Schematic illustration of the synthetic process for the H-Pd NSs, (b) TEM images of Pd NSs, (c) Etching process of Pd NSs during the first 12 days, (d) EPR spectra of Pd NSs and H-Pd NSs under different conditions ( $2 \mathrm{~W} \mathrm{~cm}^{-2}$ for NIR groups). The most favorable adsorption configurations of $\mathrm{O}_{2}$ on (e) $\mathrm{Pd}(100)$, (f) $\mathrm{Pd}(110)$ and (g) $\mathrm{Pd}(111)$ facets. Projected density of states (PDOS) of $\mathrm{O}_{2}$ on the (h) $\operatorname{Pd}(100)$, (i) $\operatorname{Pd}(110)$ and (j) $\operatorname{Pd}(111)$ facets. Reprinted with permission from [93] Copyright $@$ 2020 American Chemical Society. 
Table 2. Noble-metal nanoparticles with photocatalytic activity using light irradiation in the biological window of interest for PDT.

\begin{tabular}{cccc}
\hline Material & Light Irradiation & Catalysis Product & Reference \\
\hline $\mathrm{Au} \mathrm{NPs}$ & $532 \mathrm{~nm}$ & ${ }^{1} \mathrm{O}_{2}$ & {$[83]$} \\
\hline $\mathrm{Au} \mathrm{NRs}$ & $765 / 808 / 835 \mathrm{~nm}$ & ${ }^{1} \mathrm{O}_{2}$ & {$[85]$} \\
\hline $\mathrm{Au} \mathrm{NRs} / \mathrm{Au} N \mathrm{NP}$ & $800 \mathrm{~nm}$ & ${ }^{1} \mathrm{O}_{2}$ & {$[86]$} \\
\hline $\mathrm{Au} \mathrm{NPs}$ & Halogen lamp & ${ }^{1} \mathrm{O}_{2}$ & {$[89]$} \\
\hline $\mathrm{Au} \mathrm{NRs}$ & $915 / 940 \mathrm{~nm}$ & ${ }^{1} \mathrm{O}_{2}$ & {$[90]$} \\
\hline $\mathrm{Au} \mathrm{NUs}$ & $915 / 940 / 1064 \mathrm{~nm}$ & ${ }^{1} \mathrm{O}_{2}$ & {$[91]$} \\
\hline $\mathrm{Pd} \mathrm{NSs}$ & $808 \mathrm{~nm}$ & ${ }^{1} \mathrm{O}_{2} / \cdot \mathrm{OH}$ & {$[93]$} \\
\hline $\mathrm{Au} \mathrm{NCs}$ & $980 \mathrm{~nm}$ & ${ }^{1} \mathrm{O}_{2}$ & {$[94]$} \\
\hline $\mathrm{Au} \mathrm{NCs}$ & $1064 \mathrm{~nm}$ & ${ }^{1} \mathrm{O}_{2}$ & {$[95]$} \\
\hline $\mathrm{Ag} \mathrm{NCs}$ & White Light & ${ }^{1} \mathrm{O}_{2}$ & {$[96]$} \\
\hline $\mathrm{AuPd}$ & $808 / 1064 \mathrm{~nm}$ & $\mathrm{O}_{2}$ & {$[97]$} \\
\hline $\mathrm{AuPt}$ & $808 \mathrm{~nm}$ & $\cdot \mathrm{OH}$ & {$[98]$} \\
\hline $\mathrm{Au} \mathrm{NCs}$ & $808 \mathrm{~nm}$ & ${ }^{1} \mathrm{O}_{2}$ & {$[99]$} \\
\hline
\end{tabular}

\subsection{Photocatalytic Activity of Noble-Metal Clusters for PDT}

It has been shown how nanoparticles, particularly Au-based NPs, can selectively act as optimal inorganic photosensitizers to enhance PDT upon one and two photon irradiation and how shape and sizes affect to the capacity to selectively generate ${ }^{1} \mathrm{O}_{2}$. However, gold nanoclusters ( $\mathrm{Au} \mathrm{NCs}$ ) have been also tested as good photosensitizers to selectively promote ROS generation (Table 2). Au NCs have attracted considerable attention in biomedicine due to their biocompatibility and optical and molecule-like properties. They have size dependent optical properties with discrete electronic states which is comparable to the Fermi wavelength of conduction electrons (Figure 9) In 2009, Sakamoto et al. [100] employed single molecule fluorescence spectroscopy to study the correlation between size and photo-reactivity. Small gold nanoclusters $(n<12$ or 17) fluorescence was significantly quenched by $\mathrm{O}_{2}$ through an electron transfer mechanism [100]. However, the fluorescence intensity of bigger clusters $\left(m, 19\right.$ or 21) increased with higher concentrations of $\mathrm{O}_{2}$ thereby revealing the great relevance of Au NCs dimensions for photocatalytic applications. Other studies highlight the importance of surface facets in Au NCs to efficiently enhance ${ }^{1} \mathrm{O}_{2}$ generation [101]. Bovine Serum Albumin (BSA) capped Au NCs with different facets exposed for $\mathrm{O}_{2}$ accommodation showed different ratios for ${ }^{1} \mathrm{O}_{2}$ generation. $\mathrm{O}_{2}$ orientation in Au NCs ended up being a key parameter to enhance the PDT process. Highly active nanoclusters had a superoxol-type of $\mathrm{O}_{2}$ orientation. In contrast, the least active nanoclusters with quenched fluorescence showed a peroxo $\mathrm{O}_{2}$ orientation. They tested smaller cluster with $\mathrm{O}_{2}$ vertical adsorption (superoxo) and bigger size gold nanoclusters with peroxo-like $\mathrm{O}_{2}$ adsorption domains. Theoretical studies support the idea of controlling superoxo and peroxo-like $\mathrm{O}_{2}$ adsoption domains in smaller and bigger gold nanoclusters. The superoxo-like orientation of the smaller Au NCs leads to retaining of the identity of molecular oxygen and generates singlet states to enhance fluorescence. However, bigger $\mathrm{Au}$ NCs with peroxo-like orientation of $\mathrm{O}_{2}$ is likely to facilitate its dissociation to yield $\mathrm{O}$ radicals that initiate the oxidation of the $\mathrm{Au}-\mathrm{S}$ bonds between protein scaffolds and the encapsulated $\mathrm{Au}$ NCs to form bigger Au nanoparticles that may lead to fluorescence quenching. 


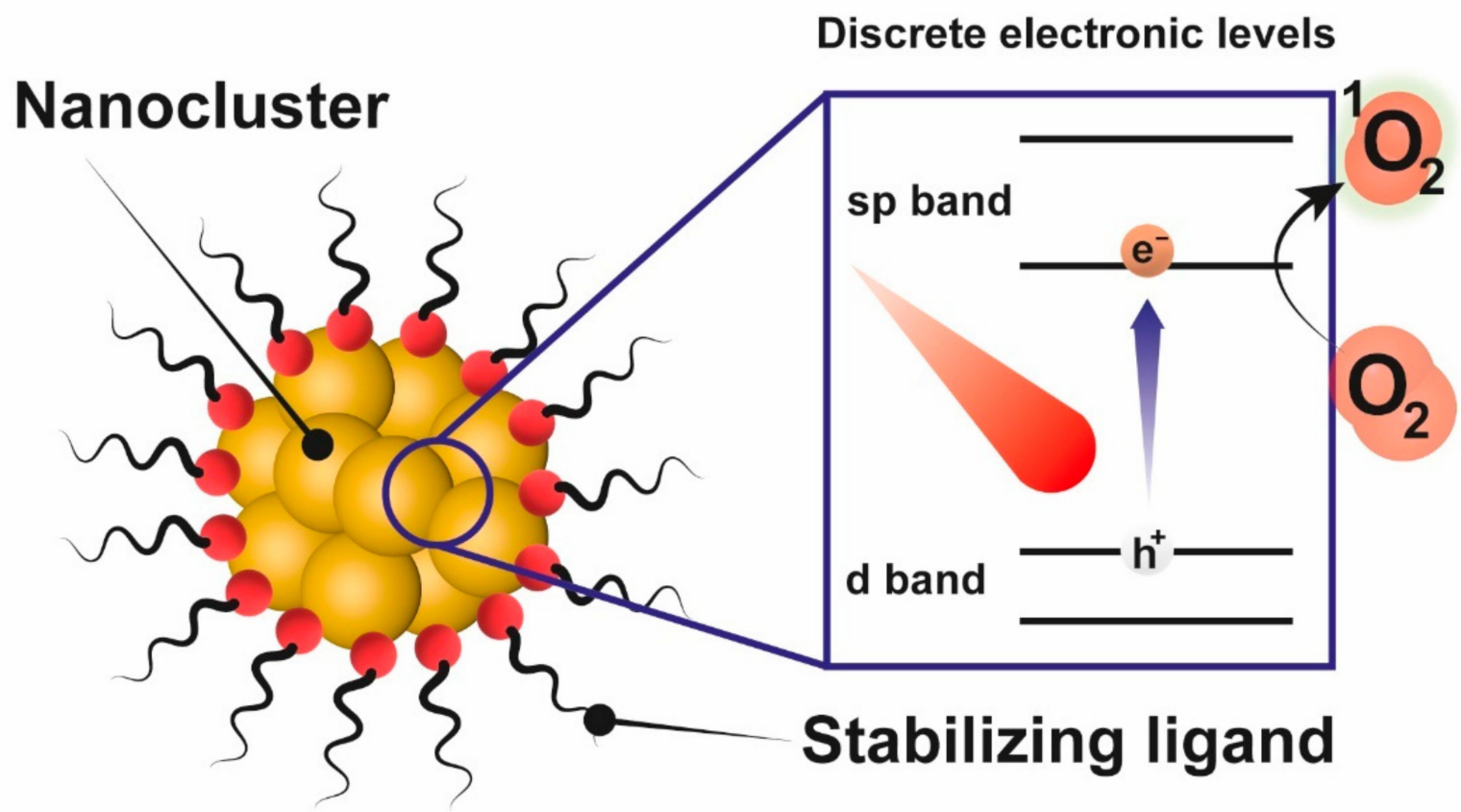

Figure 9. Noble-metal nanocluster stabilized by ligands and its electronic structure composed by discrete levels. The photoexcitation of the electrons present in $\mathrm{d}$ band entails an energetic transference to dissolved $\mathrm{O}_{2}$ to promote ${ }^{1} \mathrm{O}_{2}$ generation [102].

There has been great interest in novel design of complex metal-based nanoarchitectures in the last few years $[103,104]$. Several approaches have been developed to generate advanced hybrid-based structures with synergistic properties. It is well known that one of the most powerful strategies to induce cell death under ${ }^{1} \mathrm{O}_{2}$ generation is to target DNA $[105,106]$. Guanine nitrogen base can be further oxidized by ${ }^{1} \mathrm{O}_{2}$ to generate genotoxicity and induce cell apoptosis. Vankayala et al. [94] developed a unique design of nucleus-targeting multifunctional Au NCs to generate singlet oxygen toxic species under NIR irradiation to enhance PDT. Nucleus-targeting peptide (TAT peptide) capped Au NCs (TAT peptide-Au NCs) can selectively reach nucleus cell and successfully induce PDT under NIR light irradiation with $\mathrm{O}_{2}$ available to efficiently destruct cancer cells without the co-presence of any organic photosensitizer. Confocal fluorescence images revealed the peptide induced selective targeting of HeLa cell nucleus and ${ }^{1} \mathrm{O}_{2}$ generation under NIR laser irradiation (980 $\mathrm{nm} \mathrm{CW}$ laser with a power intensity of $1 \mathrm{~W} \mathrm{~cm}^{-2}$ for $5 \mathrm{~min}$ ).

Chen et al. [95] developed protein capped Au NCs to enhance PDT under NIR-II irradiation (Figure 10a,b). They used human serum albumin protein (HSA) and catalase enzymes (CAT) as capped proteins to design multifunctional gold-based nanoplatforms (Figure 10a,b). CAT enzymes can selectively react with $\mathrm{H}_{2} \mathrm{O}_{2}$ to form $\mathrm{O}_{2}$, alleviating tumor hypoxia and promoting ${ }^{1} \mathrm{O}_{2}$ generation in hypoxic areas (Figure 10c). It was observed how HSA capped Au NCs did not yield ${ }^{1} \mathrm{O}_{2}$ efficiently when $\mathrm{H}_{2} \mathrm{O}_{2}$ was added. However, HSA/CAT functionalized Au NCs effectively improved ${ }^{1} \mathrm{O}_{2}$ generation under irradiation when $\mathrm{H}_{2} \mathrm{O}_{2}$ was added. The multienzyme organic-inorganic hybrid (i.e., BSA/CAT capped $\mathrm{Au}$ NCs) could efficiently induce decomposition of over-expressed $\mathrm{H}_{2} \mathrm{O}_{2}$ in the tumor microenvironment (TME) to yield $\mathrm{O}_{2}$ (Figure 10d-g). 
a)
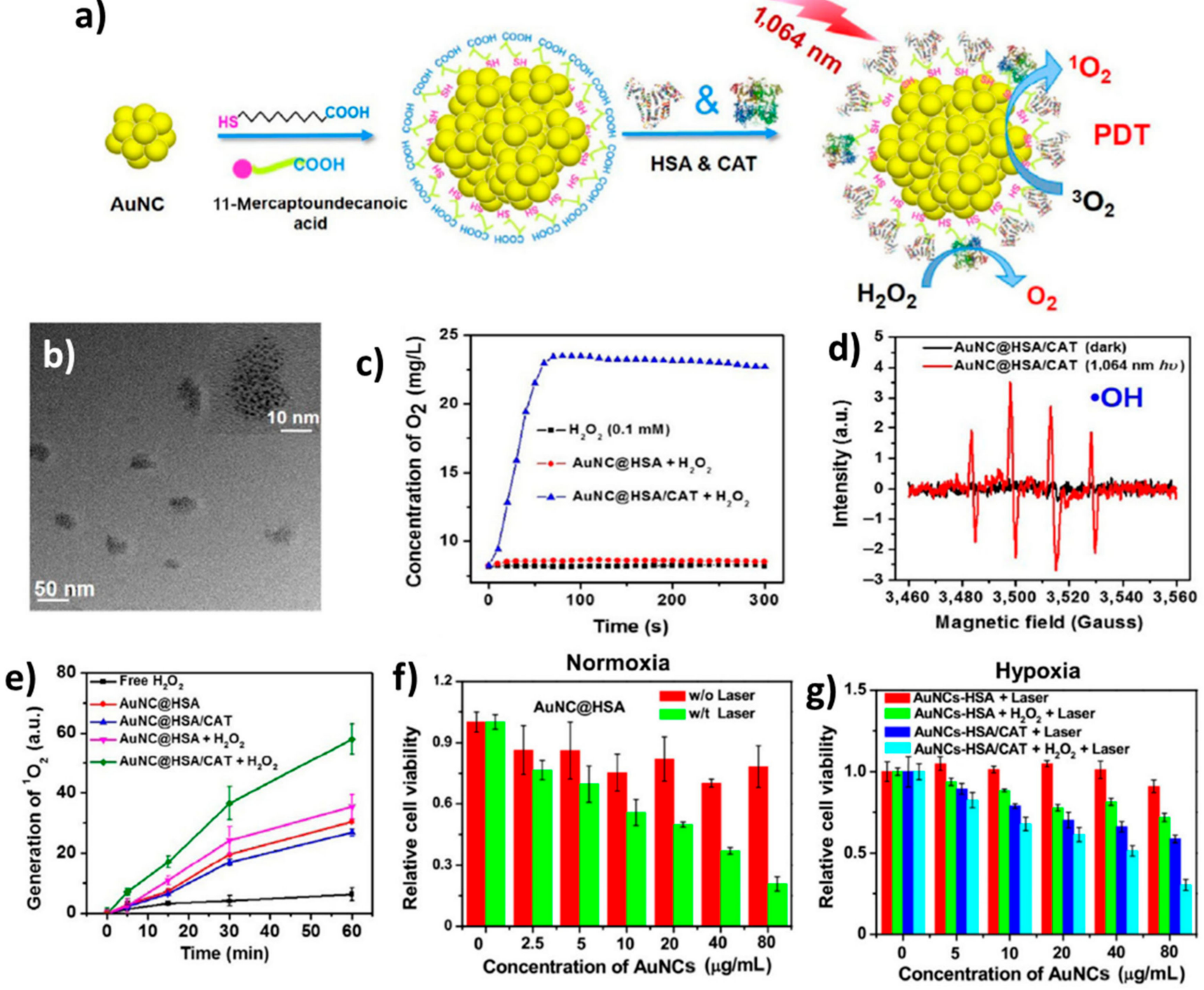

Figure 10. (a) Schematic illustration of the synthesis and synergetic therapeutic effect of Au NC@HSA/CAT nanoparticles; (b) TEM image of Au NC@HSA/CAT nanoparticles; (c) $\mathrm{O}_{2}$ generation in $\mathrm{H}_{2} \mathrm{O}_{2}$ solutions $(100 \mu \mathrm{M})$ incubated with Au NC@HSA or Au NC@HSA/CAT; (d) The generation of $\bullet \mathrm{OH}$ determined by EPR spectroscopy to measure DMPO-OH adducts in an aqueous solution containing 0.1 M DMPO; (e) The generation of ${ }^{1} \mathrm{O}_{2}$ determined by the increased SOSG fluorescence, for Au NC@HSA or Au NC@HSA/CAT, with or without addition of $\mathrm{H}_{2} \mathrm{O}_{2}$; (f) Relative viabilities of 4T1 cells after incubation with Au NC@HSA or Au NC@HSA/CAT with or without the addition of $\mathrm{H}_{2} \mathrm{O}_{2}$ after 1064-nm laser irradiation $\left(0.2 \mathrm{~W} \mathrm{~cm}^{-2}, 20 \mathrm{~min}\right)$ under the hypoxic conditions; (g) Relative viabilities of 4T1 cells after incubation with Au NC@HSA with or without NIR-II laser irradiation (1064 nm, $0.02 \mathrm{Wcm}^{-2}, 20 \mathrm{~min}$ ) under the normoxic conditions. Reprinted with permission from [95] Copyright (C) 2017 Tsinghua University Press and Springer-Verlag GmbH Germany, part of Springe Nature.

Based on a preliminary study, they activated $\mathrm{O}_{2}$ by Au NCs under light irradiation to form ROS [107]. They confirmed the ROS generation under NIR II light excitation at $1064 \mathrm{~nm}$ by EPR spectroscopy. This can be a great treatment advantage given the importance of $\mathrm{O}_{2}$ for ROS-dependent therapies like PDT in hypoxic tumor ambient.

Although Au NCs have attracted the attention of many researchers in the last few years, Ag nanoclusters (Ag NCs) have also been postulated as a promising alternative to selectively enhance PDT in cancer treatment. Yu et al. [96] developed a BSA-capped 
silver nanocluster (BSA-Ag 13 NCs) as an effective ${ }^{1} \mathrm{O}_{2}$ generator for PDT upon irradiation with a $150 \mathrm{~mW}$ white light source $\left(\approx 72 \mathrm{~mW} \mathrm{~cm}^{-2}\right)$. The ${ }^{1} \mathrm{O}_{2}$ generation ability of BSA$\mathrm{Ag}_{13}$ NCs was evaluated by employing 9,10-anthracenediyl-bis(methylene)dimalonic acid (ABDA) as a chemical probe for ${ }^{1} \mathrm{O}_{2}$ detection. Results confirmed that only BSA-Ag 13 could efficiently promote ${ }^{1} \mathrm{O}_{2}$ generation under white light irradiation. Ag ions or AgNPs did not exhibit any photocatalytic response under identical experimental conditions of white light illumination. Moreover, MCF-7 cancer cells were incubated with BSA-Ag 13 NCs and about $50 \%$ damage cell was achieved with light. The authors attributed this response to a unique energy diagram of the BSA-Ag $\mathrm{Ag}_{13} \mathrm{NC}$ [96]. Upon photoexcitation a small portion (QY of $0.4 \%$ ) of singly excited electrons underwent radiative relaxation, while a large portion of them transited to triplet states via intersystem crossing. These triplet states were capable of generate ${ }^{1} \mathrm{O}_{2}$ readily with high ${ }^{1} \mathrm{O}_{2}$ generation efficiency.

\subsection{Bimetallic Photocatalysts for Cancer Therapy}

There exist other relevant reactions where a photocatalytic process can improve the efficacy of other complementary therapies to PDT. The combination of more than one metallic component can be beneficial and synergistic. Photocatalytic decomposition of $\mathrm{H}_{2} \mathrm{O}_{2}$ to selectively generating molecular oxygen improves $\mathrm{O}_{2}$ dependence therapies such as radiotherapy. Yang et al. [97] developed a novel Pd@Au nanodisk (ND) with NIR responsive photocatalytic activity. These nanodisks were irradiated with 808 or $1064 \mathrm{~nm}$ laser to selectively photocatalyze $\mathrm{H}_{2} \mathrm{O}_{2}$ to yield $\mathrm{O}_{2}$. NIR laser irradiation promoted a synergetic photocatalytic reaction to form $\mathrm{O}_{2}$, alleviating tumor hypoxia and improving $\mathrm{O}_{2}$ dependent therapies such as radiotherapy (RT). In vivo studies revealed how tumor depletion was dramatically improved when RT was combined with NIR II irradiation, increasing $\mathrm{O}_{2}$ concentration by photocatalytic reaction of the Pd@Au NDs with $\mathrm{H}_{2} \mathrm{O}_{2}$. Liu et al. [98] studied the influence of Au@Pt NPs to selectively enhance ROS generation under NIR irradiation. Au@Pt nanoparticles were tested for methylene blue (MB) degradation with/out laser irradiation and $\mathrm{H}_{2} \mathrm{O}_{2}$. As a result, the $\mathrm{MB}$ degradation was enhanced in the presence of $\mathrm{Au} @ \mathrm{Pt}$ NPs in contact with $\mathrm{H}_{2} \mathrm{O}_{2}$ and irradiated with $808 \mathrm{~nm}$ NIR laser.

\section{Engineering Heterojunctions to Expand the Photocatalytic Response of Inorganic Semiconductors}

A wide range of different low $\mathrm{E}_{\mathrm{g}}$ semiconductor and noble metal photocatalysts have been successfully evaluated in vivo for cancer treatments, especially in the context of PDT. Nevertheless, semiconductors usually face an important drawback regarding to charge recombination phenomena [17-19] while the products obtained using noblemetals as photocatalyst are not the most reactive ones (see Table 3). An efficient strategy to enhance charge separation consists in combining different photocatalysts to form a variety of heterostructures: Type-II heterojunctions, Z-schemes and semiconductor-metal heterojunctions. Some photocatalysts based on the construction of heterojunctions applied for PDT are listed in Table 3. 
Table 3. Heterojunctions with photocatalytic activity using light irradiation in the biological window of interest for PDT.

\begin{tabular}{|c|c|c|c|c|c|}
\hline Photocatalyst & Heterostructure Type & $\begin{array}{c}\text { Measured Band } \\
\text { Gap }\left(E_{g}\right)(e V)\end{array}$ & Light Irradiation & Catalysis Products & Reference \\
\hline $\mathrm{As} / \mathrm{As}_{\mathrm{x}} \mathrm{O}_{\mathrm{y}}$ & Heterojunction- II & $1.4 / 1.7$ & $660 \mathrm{~nm}$ & $\bullet \mathrm{O}_{2}^{-},{ }^{1} \mathrm{O}_{2}, \mathrm{GSSG}$ & [108] \\
\hline $\mathrm{BiOI} / \mathrm{BiOIO}_{3}$ & Heterojunction- II & $1.70 / 3.05$ & $650 \mathrm{~nm}$ & $\mathrm{O}_{2}, \bullet \mathrm{OH},{ }^{1} \mathrm{O}_{2}$ & [109] \\
\hline $\mathrm{BiOI} / \mathrm{Bi}_{2} \mathrm{~S}_{3}$ & Heterojunction- II & 1.63 & $808 \mathrm{~nm}$ & $\bullet \mathrm{OH}, \bullet \mathrm{O}_{2}^{-}$ & [110] \\
\hline SbNSs-THPP 1 & Z-scheme & 1.75 & $660+808$ & $\bullet \mathrm{O}_{2}^{-},{ }^{1} \mathrm{O}_{2}$ & [111] \\
\hline $\mathrm{Fe}_{2} \mathrm{O}_{3}-\mathrm{FeS}_{2}$ & Z-scheme & $2.1 / 0.90$ & $650+808$ & $\bullet \mathrm{O}_{2}^{-}, \bullet \mathrm{OH}$ & [112] \\
\hline $\mathrm{Bi}_{2} \mathrm{~S}_{3}-\mathrm{Bi}$ & Z-scheme & $1.41 / 0.60$ & 808 & $\bullet \mathrm{O}_{2}^{-}, \bullet \mathrm{OH}, \mathrm{O}_{2}$ & [113] \\
\hline $\mathrm{g}-\mathrm{C}_{3} \mathrm{~N}_{4}-\mathrm{Cu}_{3} \mathrm{P}$ & Z-scheme & $3.0 / 1.66$ & 980 (UCNPs) & $\bullet \mathrm{O}_{2}^{-}, \mathrm{GSSG}, \mathrm{H}_{2}$ & [114] \\
\hline $\mathrm{SnS}_{1.68} \mathrm{WO}_{2.41}$ & Z-scheme & $1.49 / 2.43$ & 808 & GSSG, $\mathrm{H}_{2}$ & {$[23]$} \\
\hline $\mathrm{Ni}_{3} \mathrm{~S}_{2}-\mathrm{Cu}_{1.8} \mathrm{~S}$ & Z-scheme & $1.50 / 1.47$ & 808 & $\mathrm{O}_{2}, \bullet \mathrm{OH}$ & [115] \\
\hline $\mathrm{Cu}_{2} \mathrm{MoS}_{4} / \mathrm{Au}$ & Semiconductor/Metal & - & 808 & $\bullet \mathrm{O}_{2}^{-}, \bullet \mathrm{OH}$ & [116] \\
\hline $\mathrm{B}-\mathrm{TiO}_{2-\mathrm{x}} / \mathrm{Au}_{25}$ & Semiconductor/Metal & 1.23 & 808 & $\bullet \mathrm{O}_{2}^{-}, \bullet \mathrm{OH}$ & [117] \\
\hline $\mathrm{MoSe}_{2} / \mathrm{Au}$ & Semiconductor/Metal & 1.52 & 808 & $\begin{array}{c}\bullet \mathrm{OH} \text {, gluconic } \\
\text { acid, } \mathrm{H}_{2} \mathrm{O}_{2}\end{array}$ & [118] \\
\hline
\end{tabular}

\subsection{Type-II Heterojunctions Applied in Cancer Therapy}

Type II-heterojunctions consist in the combination of two semiconductors (denoted as semiconductor I and II), where $\mathrm{E}_{\mathrm{CB}, \mathrm{I}}>\mathrm{E}_{\mathrm{CB}, \mathrm{II}}$ and $\mathrm{E}_{\mathrm{VB}, \mathrm{I}}>\mathrm{E}_{\mathrm{VB}, \mathrm{II}}$ (Figure 11a). After the photogeneration of charge carriers, $\mathrm{e}^{-}$are transferred to the semiconductor II and $\mathrm{h}^{+}$to semiconductor I, achieving a more efficient spatial separation of charges leading to enhanced photocatalysis. The first Type II-heterojunction applied for PDT was reported in 2019 by Zhen et al. [109] with $\mathrm{BiOI} / \mathrm{BiOIO}_{3}$ heterostructures. The band disposition of the $\mathrm{BiOI}$ nanostructure allowed the generation of pairs $\mathrm{e}^{-} / \mathrm{h}^{+}$under $650 \mathrm{~nm}$ irradiation to perform different reactions: photo-generated $\mathrm{h}^{+}$are able to produce simultaneously $\bullet \mathrm{OH}$ and $\mathrm{O}_{2}$ from $\mathrm{H}_{2} \mathrm{O}$, while the produced $\mathrm{e}^{-}$were transferred to $\mathrm{BiOIO}_{3} \mathrm{CB}$ to provoke their reaction with endogenous $\mathrm{H}_{2} \mathrm{O}_{2}$ to produce $\bullet \mathrm{OH}$. The low dosage necessary to destroy the tumor $(0.64 \mathrm{mg} / \mathrm{kg})$ endorse the heterostructure with good biocompatibility. As $/ \mathrm{As}_{\mathrm{x}} \mathrm{O}_{\mathrm{y}}$ have also been successfully applied for PDT as Type II-heterostructures [108] (Figure 11b). In this case, the heterostructure catalyzed GSH oxidation into GSSG using photogenerated As- $\mathrm{h}^{+}$, while excited $\mathrm{e}^{-}$of As were able to tranfer their energy to $\mathrm{O}_{2}$ yielding ${ }^{1} \mathrm{O}_{2}$, or being transferred to $\mathrm{CB}$ of $\mathrm{As}_{\mathrm{x}} \mathrm{O}_{\mathrm{y}}$ to react with $\mathrm{O}_{2}$ and produce $\bullet_{2}{ }^{-}$. The therapy achieved its maximum efficiency combining a $660 \mathrm{~nm}$ laser, to perform photocatalytic process, with $808 \mathrm{~nm}$ irradiation to produce heat. As $/ \mathrm{As}_{\mathrm{x}} \mathrm{O}_{\mathrm{y}}$ heterostructure exhibited a tendency to accumulate in liver, spleen and lung, but their relatively good biocompatibility and the required low dosage guarantee their biosafety. Although band disposition in type-II heterojunctions boosts charge separation, it also entails an overall decrease of reduction/oxidation potentials of $\mathrm{CB} / \mathrm{VB}$ of the photocatalyst, respectively. 


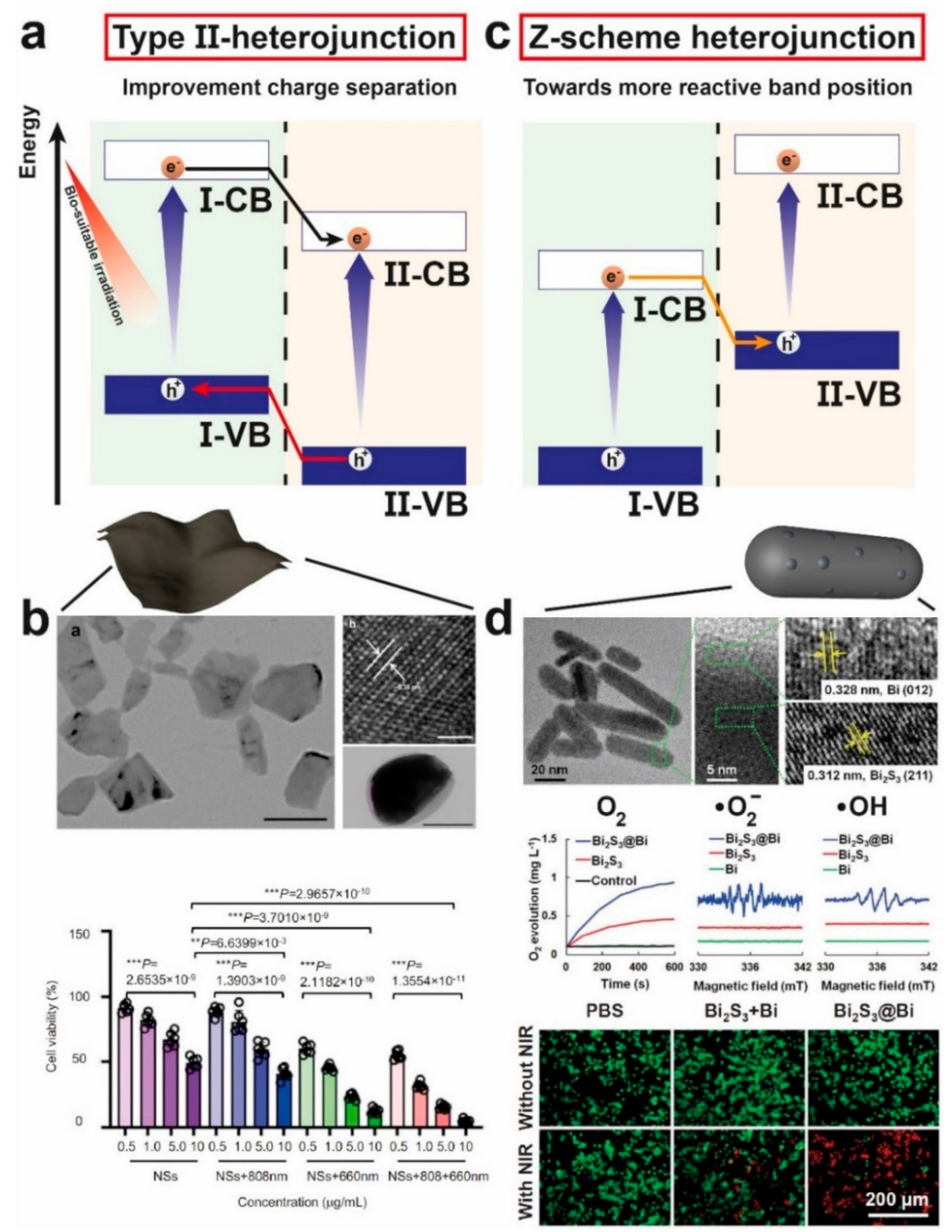

Figure 11. (a) Type-II heterojunction band structure. To boost charge separation and reduce recombination phenomena, band energy is required to be $\mathrm{VB}_{\mathrm{I}}>\mathrm{VB}_{\mathrm{II}}$ and $\mathrm{CB}_{\mathrm{I}}>\mathrm{CB}_{\mathrm{II}}$ to thermodynamically favor the migration of $\mathrm{h}^{+}$and $\mathrm{e}^{-}$to $\mathrm{VB}_{\mathrm{I}}$ and $\mathrm{CB}_{\mathrm{II}}$, respectively; (b) As $/ \mathrm{As}_{\mathrm{x}} \mathrm{O}_{\mathrm{y}}$ nanosheets type-II heterojunction applied to PDT. TEM image (scale bar $=100 \mathrm{~nm}$ ) and HR-TEM (scale bar $=1 \mathrm{~nm}$ ) of $\mathrm{As} / \mathrm{As}_{\mathrm{x}} \mathrm{O}_{\mathrm{y}}$. TEM image (scale bar $=100 \mathrm{~nm}$ ) of $\mathrm{As} / \mathrm{As}_{\mathrm{x}} \mathrm{O}_{\mathrm{y}}$ coated with cancer cell membrane nanohybrid. In vitro photocatalytic performance of $\mathrm{As} / \mathrm{As}_{\mathrm{x}} \mathrm{O}_{\mathrm{y}}$ proving the effectiveness of combining two different light irradiation to perform photocatalysis $(660 \mathrm{~nm})$ and photothermal therapy $(808 \mathrm{~nm})$. Reprinted with permission from [108]. Copyright (C 2021 Springer Nature; (c) Typical Z-scheme band structure, where the energy of each band is ordered following: $\mathrm{VB}_{\mathrm{I}}<<\mathrm{VB}_{\mathrm{II}}$ and $\mathrm{CB}_{\mathrm{I}}<<\mathrm{CB}_{\mathrm{II}}$. This band disposition favors the recombination of $\mathrm{CB}_{\mathrm{I}}$ electrons and $\mathrm{VB}_{\mathrm{II}}$ holes, achieving a adequate charge separation while improving band potentials to promote more reactive ROS generation; (d) $\mathrm{Bi}_{2} \mathrm{~S}_{3} @ \mathrm{Bi}$ nanorods (NRs) as Z-scheme applied to PDT. TEM image of $\mathrm{Bi}_{2} \mathrm{~S}_{3}$ NRs decorated with Bi dots. Simultaneous generation of $\mathrm{O}_{2}$ and ROS (i.e., $\bullet \mathrm{O}_{2}{ }^{-}$and $\bullet \mathrm{OH}$ ) under $808 \mathrm{~nm}$ irradiation. Live/dead colorimetric test of $4 \mathrm{~T} 1$ cells under different conditions, proving the efficacy of $\mathrm{Bi}_{2} \mathrm{~S}_{3} @ \mathrm{Bi}$ heterojunction provoking cell death under NIR irradiation. Reprinted with permission from [113]. Copyright (C) 2020 WILEY-VCH Verlag GmbH \& Co. KGaA, Weinheim. 


\subsection{Use of Z-Scheme Nanostructured Heterojunctions in Cancer Therapy}

Z-scheme heterostructures are often explored as an alternative to overcome the type-II heterojunction drawbacks. In these structures, both $\mathrm{CB}$ (i.e., $\mathrm{CB}_{\mathrm{I}}$ and $\mathrm{CB}_{\mathrm{II}}$ ) are excited simultaneously (Figure $11 \mathrm{c}$ ). The $\mathrm{e}^{-}$from $\mathrm{CB}_{\mathrm{I}}$ are transferred to $\mathrm{VB}_{\mathrm{II}}$, leaving stronger reduction/oxidation potentials and thus improving ROS production $[112,119,120]$. Different $Z$ scheme configurations have been successfully evaluated for PDT, including $\mathrm{Fe}_{2} \mathrm{O}_{3}-\mathrm{FeS}_{2}$ [112], SbNSs-THPP (namely, 10,15,20-tetrakis(4-hydroxyphenyl)-21H,12H-porphine) [111], $\mathrm{Bi}_{2} \mathrm{~S}_{3}$ Bi [113], g- $\mathrm{C}_{3} \mathrm{~N}_{4}-\mathrm{Cu}_{3} \mathrm{P}$ [114], $\mathrm{SnS}_{1.68}-\mathrm{WO}_{2.41}$ [23] or $\mathrm{Ni}_{3} \mathrm{~S}_{2}-\mathrm{Cu}_{1.8} \mathrm{~S}$ [115]. In this case, most of the Z-scheme nanostructures could perform under $808 \mathrm{~nm}$ irradiation in comparison with type-II heterostructures, which could work under $650 \mathrm{~nm}$. However, the complexity of biological systems (i.e., different cell lines, tumor models and so on) and the lack of systematic experiments currently prevent a fair comparison among different photocatalysts. Cheng et al. [113] fabricated $\mathrm{Bi}_{2} \mathrm{~S}_{3}$-Bi Z-scheme with different photocatalytic responses (Figure 11d), including $\mathrm{O}_{2}, \bullet \mathrm{O}_{2}{ }^{-}$and $\bullet \mathrm{OH}$ generation under $808 \mathrm{~nm}$ irradiation. They highlighted the importance of the contact between photocatalysts in the heterostructure (i.e., $\mathrm{Bi}_{2} \mathrm{~S}_{3}$ and $\mathrm{Bi}$ ) proving the absence of in vitro and in vivo therapeutic effect when both single-phased materials were introduced simultaneously (Figure 11d). Following the trend found in low $\mathrm{E}_{\mathrm{g}}$ photocatalysts and type-II heterostructures, Z-schemes also demonstrate the capability to photooxidize GSH into GSSG, while generating $\mathrm{H}_{2}$ from $\mathrm{H}^{+}[23,114]$. It has been demonstrated that $\mathrm{H}_{2}$ (Figure 2) targets mitochondria and may induce cell apoptosis through disruption of cellular energy metabolism by hindering ATP production [121,122].

\subsection{Semiconductor-Noble Metal Heterojunctions for PDT}

Another widespread strategy to maximize charge separation consists in generating metal-semiconductor heterostructures. Noble metal nanoparticles such as Au possess large work functions (broadly speaking, remove an electron from their surface is a highly energetic process) and thus, they may greatly attract electrons to achieve a successful charge separation (Figure 12a). Lin group [116] demonstrate this concept by fabricating $\mathrm{Cu}_{2} \mathrm{MoS}_{4}-\mathrm{Au}$ heterostructure (Figure $12 \mathrm{~b}$ ), which significantly enhanced its photocatalytic activity generating $\bullet \mathrm{O}_{2}{ }^{-}$and $\bullet \mathrm{OH}$ in the presence of Au nanoparticles. Au acted as sinker of the photogenerated $\mathrm{e}^{-}$to both boost charge separation and interact with $\mathrm{H}_{2} \mathrm{O}_{2} / \mathrm{O}_{2}$ to produce ROS. In vivo experiments demonstrated the efficacy of this treatment without altering healthy tissues (Figure 11b).

At the interface between metal nanostructures and another media exists a delocalized coherent electron oscillation known as localized surface plasmon resonance (LSPR) [123]. Excitation of these electrons with a suitable wavelength excite them and favors their migration to the CB of the semiconductor, a phenomenon known as "hot-electron injection" [124] (Figure 12c). Li et al. fabricated $\mathrm{MoSe}_{2}$-Au heterostructures with the capability of injecting hot-electrons from $\mathrm{Au}$ in the $\mathrm{MoSe}_{2} \mathrm{CB}$ under $808 \mathrm{~nm}$ irradiation [118]. Apart from enhancing the photocatalytic activity of $\mathrm{MoSe}_{2}$ due hot electron process, $\mathrm{Au}$ is a typical catalyst to assist glucose oxidation $[125,126]$. Removing glucose from tumors interfere in their energy metabolism and has been proved an alternative therapeutic approach [127]. $\mathrm{MoSe}_{2}$-Au photocatalyst effectively produce ROS under NIR irradiation while catalyzes glucose oxidation. This photoactivity exhibited an effective in vivo tumor inhibition (Figure 12d). 


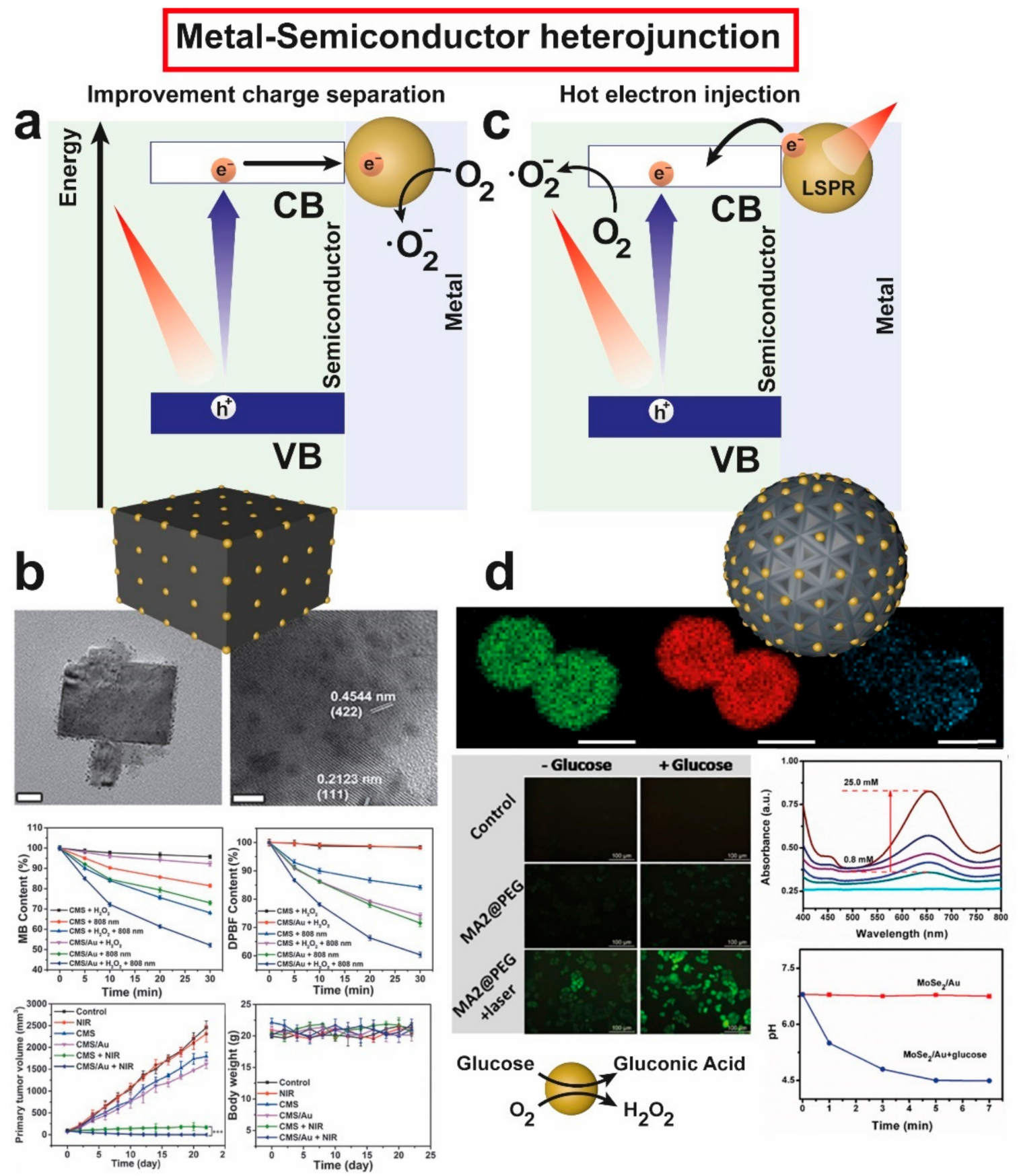

Figure 12. (a) Metal-semiconductor heterojunction band diagram. The presence of a noble-metal nanoparticle with a large work function $(\phi)$ since Au accepts photogenerated e- to promote charge separation phenomena.; (b) TEM images of $\mathrm{Cu}_{2} \mathrm{MoS}_{4}$-Au heterostructure (left scale bar: $10 \mathrm{~nm}$, right scale bar: $5 \mathrm{~nm}$ ). Photogeneration of $\bullet \mathrm{OH}$ and $\bullet \mathrm{O}_{2}{ }^{-}$under NIR irradiation, enhanced by the introduction of $\mathrm{Au}$ nanoparticles in the nanostructure. Tumor inhibition of $\mathrm{CuMoS}_{4}$-Au under $808 \mathrm{~nm}$ irradiation, without altering significatively mice body weight. Reprinted with permission from [116]. Copyright (c) 2020 WILEY-VCH Verlag GmbH \& Co. KGaA, Weinheim; (c) Electron transference from the noble metal nanoparticle to CB of semiconductor through hot electron mechanism [123] (d) $\mathrm{MoSe}_{2}$-Au nanoparticles elemental mapping (from left to right Mo, Se and Au) (scale bar: $200 \mathrm{~nm}$ ). Glucose oxidase-like activity of Au nanoparticles on $\mathrm{MoSe}_{2}$ surface, boosted by NIR irradiation for in vitro ROS generation. In vivo tumor inhibition by combining $\mathrm{MoSe}_{2}-\mathrm{Au}$ with NIR irradiation. $\mathrm{pH}$ decreases in the presence of $\mathrm{MoSe}_{2}$-Au catalyst, indicating the generation of gluconic acid as glucose oxidation product. Reprinted with permission from [118]. Copyright (C) 2021 Elsevier B.V. 


\section{Conclusions}

The use of nanostructured photocatalysts in cancer therapy has paved the way to explore new and exciting therapeutic alternatives to treat cancer with the aid of visible and NIR irradiation light sources that can boost the in-situ generation of ROS in the tumor environment. Engineering smart nanomaterials towards synergistic heterostructure is key to overcome the drawbacks of organic photosensitizers applied in PDT or the limitations of single-phased materials. Likewise, exploring catalytic mechanisms that are well established in other catalytic fields (i.e., electrocatalysis) represents an appealing and exciting field when narrowed down to a cancer cell scenario. Classic reactions such as water splitting (i.e., $\mathrm{H}_{2} \mathrm{O}$ transformation in $\left.\mathrm{O}_{2}\right)$ or hydrogen evolution $\left(\mathrm{H}_{2}\right.$ generation from $\left.\mathrm{H}^{+}\right)$are being now exploited to perform cancer therapy given favorable conditions in the TME. Finally, novel reactions in photocatalysis that directly target key metabolites (i.e., GSH, glucose) or favor biorthogonal processes are also of high interest in the field of cancer therapy and worth exploring in the forthcoming years.

Author Contributions: Conceptualization, J.B.-A. and J.L.H.; writing-original draft preparation, J.I.G.-P., J.B.-A. and J.L.H.; writing-review and editing, J.L.H. All authors have read and agreed to the published version of the manuscript.

Funding: This research was funded by the European Research Council (ERC) through an Advanced Research Grant (CADENCE, grant number 742684). The APC was waived by the journal.

Data Availability Statement: No new data were created or analyzed in this study. Data sharing is not applicable to this review.

Acknowledgments: The authors thank the Platform of Production of Biomaterials and Nanoparticles of the NANBIOSIS-ICTS of the CIBER in BioEngineering, Biomaterials \& Nanomedicine (CIBERBBN). J.B.-A. acknowledges the Spanish Government for a PhD predoctoral grant (FPU18/04618). J.I.G.-P. thanks the Regional Government of Aragon (DGA) for granting a PhD predoctoral contract. The Regional Government of Aragon is also acknowledged.

Conflicts of Interest: The authors declare no conflict of interest.

\section{References}

1. International Agency for Research Cancer (IARC)-WHO (Biennial Report 20-21). Available online: https: / / www.iarc.who.int/ biennial-report-2020-2021web/ (accessed on 24 January 2022).

2. Gai, S.; Yang, G.; Yang, P.; He, F.; Lin, J.; Jin, D.; Xing, B. Recent advances in functional nanomaterials for light-triggered cancer therapy. Nano Today 2018, 19, 146-187. [CrossRef]

3. Ash, C.; Dubec, M.; Donne, K.; Bashford, T. Effect of wavelength and beam width on penetration in light-tissue interaction using computational methods. Lasers Med. Sci. 2017, 32, 1909-1918. [CrossRef] [PubMed]

4. Alsaab, H.O.; Alghamdi, M.S.; Alotaibi, A.S.; Alzhrani, R.; Alwuthaynani, F.; Althobaiti, Y.S.; Almalki, A.H.; Sau, S.; Iyer, A.K. Progress in clinical trials of photodynamic therapy for solid tumors and the role of nanomedicine. Cancers 2020, $12,2793$. [CrossRef] [PubMed]

5. Phua, S.Z.F.; Xue, C.; Lim, W.Q.; Yang, G.; Chen, H.; Zhang, Y.; Wijaya, C.F.; Luo, Z.; Zhao, Y. Light-responsive prodrug-based supramolecular nanosystems for site-specific combination therapy of cancer. Chem. Mater. 2019, 31, 3349-3358. [CrossRef]

6. $\mathrm{Wu}, \mathrm{H}$.; Minamide, T.; Yano, T. Role of photodynamic therapy in the treatment of esophageal cancer. Dig. Endosc. Off. J. Jpn. Gastroenterol. Endosc. Soc. 2019, 31, 508-516. [CrossRef]

7. Aniogo, E.C.; Plackal Adimuriyil George, B.; Abrahamse, H. The role of photodynamic therapy on multidrug resistant breast cancer. Cancer Cell Int. 2019, 19, 91. [CrossRef]

8. Nackiewicz, J.; Kliber-Jasik, M.; Skonieczna, M. A novel pro-apoptotic role of zinc octacarboxyphthalocyanine in melanoma me45 cancer cell's photodynamic therapy (PDT). J. Photochem. Photobiol. B Biol. 2019, 190, 146-153. [CrossRef]

9. Pellosi, D.S.; Tessaro, A.L.; Moret, F.; Gaio, E.; Reddi, E.; Caetano, W.; Quaglia, F.; Hioka, N. Pluronic ${ }^{\circledR}$ mixed micelles as efficient nanocarriers for benzoporphyrin derivatives applied to photodynamic therapy in cancer cells. J. Photochem. Photobiol. A Chem. 2016, 314, 143-154. [CrossRef]

10. Li, X.; Lee, S.; Yoon, J. Supramolecular photosensitizers rejuvenate photodynamic therapy. Chem. Soc. Rev. 2018, 47, 1174-1188. [CrossRef]

11. Yan, Y.; Zhang, J.; Ren, L.; Tang, C. Metal-containing and related polymers for biomedical applications. Chem. Soc. Rev. 2016, 45, 5232-5263. [CrossRef] 
12. Zhou, Z.; Song, J.; Nie, L.; Chen, X. Reactive oxygen species generating systems meeting challenges of photodynamic cancer therapy. Chem. Soc. Rev. 2016, 45, 6597-6626. [CrossRef] [PubMed]

13. Fang, J.; Nakamura, H.; Maeda, H. The EPR effect: Unique features of tumor blood vessels for drug delivery, factors involved, and limitations and augmentation of the effect. Adv. Drug Deliv. Rev. 2011, 63, 136-151. [CrossRef] [PubMed]

14. Wade, L.G. Organic Chemistry; Pearson: London, UK, 2013.

15. Romero, N.A.; Nicewicz, D.A. Organic photoredox catalysis. Chem. Rev. 2016, 116, 10075-10166. [CrossRef]

16. Ohtani, B. Chapter 10-Photocatalysis by inorganic solid materials: Revisiting its definition, concepts, and experimental procedures. In Advances in Inorganic Chemistry; van Eldik, R., Stochel, G., Eds.; Academic Press: Cambridge, MA, USA, 2011; Volume 63, pp. 395-430.

17. Tian, J.; Hao, P.; Wei, N.; Cui, H.; Liu, H. 3D Bi2MoO6 nanosheet/TiO2 nanobelt heterostructure: Enhanced photocatalytic activities and photoelectochemistry performance. ACS Catal. 2015, 5, 4530-4536. [CrossRef]

18. Fu, J.; Yu, J.; Jiang, C.; Cheng, B. g-C3N4-based heterostructured photocatalysts. Adv. Energy Mater. 2018, 8, 1701503. [CrossRef]

19. Yuan, Y.-P.; Ruan, L.-W.; Barber, J.; Joachim Loo, S.C.; Xue, C. Hetero-nanostructured suspended photocatalysts for solar-to-fuel conversion. Energy Environ. Sci. 2014, 7, 3934-3951. [CrossRef]

20. Krumova, K.; Cosa, G. Chapter 1 Overview of Reactive Oxygen Species. In Singlet Oxygen: Applications in Biosciences and Nanosciences, Volume 1; The Royal Society of Chemistry: London, UK, 2016; Volume 1, pp. 1-21.

21. Chen, W.; Sun, Z.; Jiang, C.; Sun, W.; Yu, B.; Wang, W.; Lu, L. An all-in-one organic semiconductor for targeted photoxidation catalysis in hypoxic tumor. Angew. Chem. Int. Ed. 2021, 60, 16641-16648. [CrossRef]

22. Ding, Y.; Dai, Y.; Wu, M.; Li, L. Glutathione-mediated nanomedicines for cancer diagnosis and therapy. Chem. Eng. J. 2021, 426, 128880. [CrossRef]

23. Zhao, B.; Wang, Y.; Yao, X.; Chen, D.; Fan, M.; Jin, Z.; He, Q. Photocatalysis-mediated drug-free sustainable cancer therapy using nanocatalyst. Nat. Commun. 2021, 12, 1345. [CrossRef]

24. Höckel, M.; Vaupel, P. Tumor hypoxia: Definitions and current clinical, biologic, and molecular aspects. JNCI J. Natl. Cancer Inst. 2001, 93, 266-276. [CrossRef]

25. Ruan, C.; Su, K.; Zhao, D.; Lu, A.; Zhong, C. Nanomaterials for tumor hypoxia relief to improve the efficacy of ROS-generated cancer therapy. Front. Chem. 2021, 9, 649158. [CrossRef] [PubMed]

26. Nelson, D.L.; Lehninger, A.L.; Cox, M.M. Lehninger Principles of Biochemistry; W.H. Freeman: New York, NY, USA, 2008.

27. Balendiran, G.K.; Dabur, R.; Fraser, D. The role of glutathione in cancer. Cell Biochem. Funct. 2004, 22, 343-352. [CrossRef] [PubMed]

28. Dykman, L.; Khlebtsov, N. Gold nanoparticles in biomedical applications: Recent advances and perspectives. Chem. Soc. Rev. 2012, 41, 2256-2282. [CrossRef]

29. Guo, J.; Rahme, K.; He, Y.; Li, L.L.; Holmes, J.D.; O’Driscoll, C.M. Gold nanoparticles enlighten the future of cancer theranostics. Int. J. Nanomed. 2017, 12, 6131-6152. [CrossRef] [PubMed]

30. Pedone, D.; Moglianetti, M.; De Luca, E.; Bardi, G.; Pompa, P.P. Platinum nanoparticles in nanobiomedicine. Chem. Soc. Rev. 2017, 46, 4951-4975. [CrossRef]

31. Ma, N.; Wu, F.-G.; Zhang, X.; Jiang, Y.-W.; Jia, H.-R.; Wang, H.-Y.; Li, Y.-H.; Liu, P.; Gu, N.; Chen, Z. Shape-dependent radiosensitization effect of gold nanostructures in cancer radiotherapy: Comparison of gold nanoparticles, nanospikes, and nanorods. ACS Appl. Mater. Interfaces 2017, 9, 13037-13048. [CrossRef]

32. Cao, Y.; Wu, T.; Dai, W.; Dong, H.; Zhang, X. TiO2 nanosheets with the au nanocrystal-decorated edge for mitochondria-targeting enhanced sonodynamic therapy. Chem. Mater. 2019, 31, 9105-9114. [CrossRef]

33. Gu, T.; Wang, Y.; Lu, Y.; Cheng, L.; Feng, L.; Zhang, H.; Li, X.; Han, G.; Liu, Z. Platinum nanoparticles to enable electrodynamic therapy for effective cancer treatment. Adv. Mater. 2019, 31, 1806803. [CrossRef]

34. Li, J.; Liu, W.; Wu, X.; Gao, X. Mechanism of $\mathrm{pH}$-switchable peroxidase and catalase-like activities of gold, silver, platinum and palladium. Biomaterials 2015, 48, 37-44. [CrossRef]

35. Chen, Q.; He, S.; Zhang, F.; Cui, F.; Liu, J.; Wang, M.; Wang, D.; Jin, Z.; Li, C. A versatile Pt-Ce6 nanoplatform as catalase nanozyme and NIR-II photothermal agent for enhanced PDT/PTT tumor therapy. Sci. China Mater. 2021, 64, 510-530. [CrossRef]

36. Alkilany, A.M.; Thompson, L.B.; Boulos, S.P.; Sisco, P.N.; Murphy, C.J. Gold nanorods: Their potential for photothermal therapeutics and drug delivery, tempered by the complexity of their biological interactions. Adv. Drug Deliv. Rev. 2012, 64, 190-199. [CrossRef] [PubMed]

37. He, J.-S.; Liu, S.-J.; Zhang, Y.-R.; Chu, X.-D.; Lin, Z.-B.; Zhao, Z.; Qiu, S.-H.; Guo, Y.-G.; Ding, H.; Pan, Y.-L.; et al. The application of and strategy for gold nanoparticles in cancer immunotherapy. Front. Pharmacol. 2021, 12, 1430. [CrossRef] [PubMed]

38. Ming, J.; Zhu, T.; Yang, W.; Shi, Y.; Huang, D.; Li, J.; Xiang, S.; Wang, J.; Chen, X.; Zheng, N. Pd@Pt-GOx/HA as a novel enzymatic cascade nanoreactor for high-efficiency starving-enhanced chemodynamic cancer therapy. ACS Appl. Mater. Interfaces 2020, 12, 51249-51262. [CrossRef] [PubMed]

39. Sancho-Albero, M.; Rubio-Ruiz, B.; Pérez-López, A.M.; Sebastián, V.; Martín-Duque, P.; Arruebo, M.; Santamaría, J.; Unciti-Broceta, A. Cancer-derived exosomes loaded with ultrathin palladium nanosheets for targeted bioorthogonal catalysis. Nat. Catal. 2019, 2, 864-872. [CrossRef] [PubMed] 
40. Pérez-López, A.M.; Rubio-Ruiz, B.; Valero, T.; Contreras-Montoya, R.; Álvarez de Cienfuegos, L.; Sebastián, V.; Santamaría, J.; Unciti-Broceta, A. Bioorthogonal uncaging of cytotoxic paclitaxel through Pd nanosheet-hydrogel frameworks. J. Med. Chem. 2020, 63, 9650-9659. [CrossRef]

41. Ali, M.R.K.; Wu, Y.; El-Sayed, M.A. Gold-nanoparticle-assisted plasmonic photothermal therapy advances toward clinical application. J. Phys. Chem. C 2019, 123, 15375-15393. [CrossRef]

42. Lv, Z.; He, S.; Wang, Y.; Zhu, X. Noble metal nanomaterials for nir-triggered photothermal therapy in cancer. Adv. Heal. Mater. 2021, 10, 2001806. [CrossRef]

43. Vankayala, R.; Sagadevan, A.; Vijayaraghavan, P.; Kuo, C.-L.; Hwang, K.C. Metal nanoparticles sensitize the formation of singlet oxygen. Angew. Chem. Int. Ed. 2011, 50, 10640-10644. [CrossRef]

44. Shinde, D.R.; Tambade, P.S.; Chaskar, M.G.; Gadave, K.M. Photocatalytic degradation of dyes in water by analytical reagent grades $\mathrm{ZnO}$, TiO2 and SnO2: A comparative study. Drink. Water Eng. Sci. 2017, 10, 109-117. [CrossRef]

45. Upadhyay, G.K.; Rajput, J.K.; Pathak, T.K.; Kumar, V.; Purohit, L.P. Synthesis of ZnO: $\mathrm{TiO}_{2}$ nanocomposites for photocatalyst application in visible light. Vacuum 2019, 160, 154-163. [CrossRef]

46. Kippeny, T.; Swafford, L.A.; Rosenthal, S.J. Semiconductor nanocrystals: A powerful visual aid for introducing the particle in a box. J. Chem. Educ. 2002, 79, 1094. [CrossRef]

47. Wang, H.; Yang, X.; Shao, W.; Chen, S.; Xie, J.; Zhang, X.; Wang, J.; Xie, Y. Ultrathin black phosphorus nanosheets for efficient singlet oxygen generation. J. Am. Chem. Soc. 2015, 137, 11376-11382. [CrossRef] [PubMed]

48. Dong, H.; Tang, S.; Hao, Y.; Yu, H.; Dai, W.; Zhao, G.; Cao, Y.; Lu, H.; Zhang, X.; Ju, H. Fluorescent MoS2 quantum dots: Ultrasonic preparation, up-conversion and down-conversion bioimaging, and photodynamic therapy. ACS Appl. Mater. Interfaces 2016, 8 , 3107-3114. [CrossRef] [PubMed]

49. Guo, W.; Guo, C.; Zheng, N.; Sun, T.; Liu, S. CsxWO3 nanorods coated with polyelectrolyte multilayers as a multifunctional nanomaterial for bimodal imaging-guided photothermal/photodynamic cancer treatment. Adv. Mater. 2017, $29,1604157$. [CrossRef]

50. Li, Y.; Liu, Z.; Hou, Y.; Yang, G.; Fei, X.; Zhao, H.; Guo, Y.; Su, C.; Wang, Z.; Zhong, H.; et al. Multifunctional nanoplatform based on black phosphorus quantum dots for bioimaging and photodynamic/photothermal synergistic cancer therapy. ACS Appl. Mater. Interfaces 2017, 9, 25098-25106. [CrossRef]

51. Xu, Y.; Fan, M.; Yang, W.; Xiao, Y.; Zeng, L.; Wu, X.; Xu, Q.; Su, C.; He, Q. Homogeneous carbon/potassium-incorporation strategy for synthesizing red polymeric carbon nitride capable of near-infrared photocatalytic H2 production. Adv. Mater. 2021, 33, 2101455. [CrossRef]

52. Duo, Y.; Luo, G.; Li, Z.; Chen, Z.; Li, X.; Jiang, Z.; Yu, B.; Huang, H.; Sun, Z.; Yu, X.-F. Photothermal and enhanced photocatalytic therapies conduce to synergistic anticancer phototherapy with biodegradable titanium diselenide nanosheets. Small 2021, 17, 2103239. [CrossRef]

53. Mou, J.; Lin, T.; Huang, F.; Chen, H.; Shi, J. Black titania-based theranostic nanoplatform for single NIR laser induced dual-modal imaging-guided PTT/PDT. Biomaterials 2016, 84, 13-24. [CrossRef]

54. Mou, J.; Lin, T.; Huang, F.; Shi, J.; Chen, H. A new green titania with enhanced nir absorption for mitochondria-targeted cancer therapy. Theranostics 2017, 7, 1531-1542. [CrossRef]

55. Yu, H.; Cheng, Y.; Wen, C.; Sun, Y.-Q.; Yin, X.-B. Triple cascade nanocatalyst with laser-activatable O2 supply and photothermal enhancement for effective catalytic therapy against hypoxic tumor. Biomaterials 2022, 280, 121308. [CrossRef]

56. Murakami, T.; Nakatsuji, H.; Inada, M.; Matoba, Y.; Umeyama, T.; Tsujimoto, M.; Isoda, S.; Hashida, M.; Imahori, H. Photodynamic and photothermal effects of semiconducting and metallic-enriched single-walled carbon nanotubes. J. Am. Chem. Soc. 2012, 134, 17862-17865. [CrossRef] [PubMed]

57. Kalluru, P.; Vankayala, R.; Chiang, C.-S.; Hwang, K.C. Nano-graphene oxide-mediated In vivo fluorescence imaging and bimodal photodynamic and photothermal destruction of tumors. Biomaterials 2016, 95, 1-10. [CrossRef] [PubMed]

58. Shi, J.; Wang, L.; Gao, J.; Liu, Y.; Zhang, J.; Ma, R.; Liu, R.; Zhang, Z. A fullerene-based multi-functional nanoplatform for cancer theranostic applications. Biomaterials 2014, 35, 5771-5784. [CrossRef] [PubMed]

59. Ortega-Liebana, M.C.; Encabo-Berzosa, M.M.; Casanova, A.; Pereboom, M.D.; Alda, J.O.; Hueso, J.L.; Santamaria, J. Upconverting carbon nanodots from Ethylenediaminetetraacetic Acid (EDTA) as near-infrared activated phototheranostic agents. Chem.-A Eur. J. 2019, 25, 5539-5546. [CrossRef] [PubMed]

60. Li, Y.; Zheng, X.; Zhang, X.; Liu, S.; Pei, Q.; Zheng, M.; Xie, Z. Porphyrin-based carbon dots for photodynamic therapy of hepatoma. Adv. Healthc. Mater. 2017, 6, 1600924. [CrossRef]

61. Zhang, K.; Meng, X.; Cao, Y.; Yang, Z.; Dong, H.; Zhang, Y.; Lu, H.; Shi, Z.; Zhang, X. Metal-Organic framework nanoshuttle for synergistic photodynamic and low-temperature photothermal therapy. Adv. Funct. Mater. 2018, 28, 1804634. [CrossRef]

62. Zheng, X.; Wang, L.; Liu, M.; Lei, P.; Liu, F.; Xie, Z. Nanoscale mixed-component metal-organic frameworks with photosensitizer spatial-arrangement-dependent photochemistry for multimodal-imaging-guided photothermal therapy. Chem. Mater. 2018, 30, 6867-6876. [CrossRef]

63. Li, S.-H.; Yang, W.; Liu, Y.; Song, X.-R.; Liu, R.; Chen, G.; Lu, C.-H.; Yang, H.-H. Engineering of tungsten carbide nanoparticles for imaging-guided single $1064 \mathrm{~nm}$ laser-activated dual-type photodynamic and photothermal therapy of cancer. Nano Res. 2018, 11, 4859-4873. [CrossRef] 
64. Hou, H.; Wang, Z.; Ma, Y.; Yu, K.; Zhao, J.; Lin, H.; Qu, F. NIR-driven intracellular photocatalytic oxygen-supply on metallic molybdenum carbide@N-carbon for hypoxic tumor therapy. J. Colloid Interface Sci. 2022, 607, 1-15. [CrossRef]

65. Lv, R.; Yang, D.; Yang, P.; Xu, J.; He, F.; Gai, S.; Li, C.; Dai, Y.; Yang, G.; Lin, J. Integration of upconversion nanoparticles and ultrathin black phosphorus for efficient photodynamic theranostics under $808 \mathrm{~nm}$ near-infrared light irradiation. Chem. Mater. 2016, 28, 4724-4734. [CrossRef]

66. Tran, V.; Soklaski, R.; Liang, Y.; Yang, L. Layer-controlled band gap and anisotropic excitons in few-layer black phosphorus. Phys. Rev. B 2014, 89, 235319. [CrossRef]

67. Wang, Y.L.; Nie, T.; Li, Y.H.; Wang, X.L.; Zheng, L.R.; Chen, A.P.; Gong, X.Q.; Yang, H.G. Black tungsten nitride as a metallic photocatalyst for overall water splitting operable at up to $765 \mathrm{~nm}$. Angew. Chem. (Int. Ed. Engl.) 2017, 56, 7430-7434. [CrossRef] [PubMed]

68. Nocito, G.; Calabrese, G.; Forte, S.; Petralia, S.; Puglisi, C.; Campolo, M.; Esposito, E.; Conoci, S. Carbon dots as promising tools for cancer diagnosis and therapy. Cancers 2021, 13, 1991. [CrossRef]

69. Wang, J.; Xu, M.; Wang, D.; Li, Z.; Primo, F.L.; Tedesco, A.C.; Bi, H. Copper-doped carbon dots for optical bioimaging and photodynamic therapy. Inorg. Chem. 2019, 58, 13394-13402. [CrossRef]

70. Chen, G.; Qiu, H.; Prasad, P.N.; Chen, X. Upconversion nanoparticles: Design, nanochemistry, and applications in theranostics. Chem. Rev. 2014, 114, 5161-5214. [CrossRef] [PubMed]

71. Wang, L.; Wang, K.; He, T.; Zhao, Y.; Song, H.; Wang, H. Graphitic carbon nitride-based photocatalytic materials: Preparation strategy and application. ACS Sustain. Chem. Eng. 2020, 8, 16048-16085. [CrossRef]

72. Chan, M.-H.; Chen, C.-W.; Lee, I.J.; Chan, Y.-C.; Tu, D.; Hsiao, M.; Chen, C.-H.; Chen, X.; Liu, R.-S. Near-infrared light-mediated photodynamic therapy nanoplatform by the electrostatic assembly of upconversion nanoparticles with graphitic carbon nitride quantum dots. Inorg. Chem. 2016, 55, 10267-10277. [CrossRef] [PubMed]

73. Chan, M.-H.; Pan, Y.-T.; Lee, I.-J.; Chen, C.-W.; Chan, Y.-C.; Hsiao, M.; Wang, F.; Sun, L.; Chen, X.; Liu, R.-S. Minimizing the heat effect of photodynamic therapy based on inorganic nanocomposites mediated by $808 \mathrm{~nm}$ near-infrared light. Small 2017, 13, 1700038. [CrossRef]

74. Feng, L.; He, F.; Yang, G.; Gai, S.; Dai, Y.; Li, C.; Yang, P. NIR-driven graphitic-phase carbon nitride nanosheets for efficient bioimaging and photodynamic therapy. J. Mater. Chem. B 2016, 4, 8000-8008. [CrossRef]

75. Brown, J.M. Tumor hypoxia in cancer therapy. Methods Enzymol. 2007, 435, 297-321. [CrossRef]

76. Tetsuka, H.; Asahi, R.; Nagoya, A.; Okamoto, K.; Tajima, I.; Ohta, R.; Okamoto, A. Optically tunable amino-functionalized graphene quantum dots. Adv. Mater. 2012, 24, 5333-5338. [CrossRef] [PubMed]

77. Zeng, J.-Y.; Zhang, M.-K.; Peng, M.-Y.; Gong, D.; Zhang, X.-Z. Porphyrinic metal-organic frameworks coated gold nanorods as a versatile nanoplatform for combined photodynamic/photothermal/chemotherapy of tumor. Adv. Funct. Mater. $2018,28,1705451$. [CrossRef]

78. Wei, J.; Li, J.; Sun, D.; Li, Q.; Ma, J.; Chen, X.; Zhu, X.; Zheng, N. A novel theranostic nanoplatform based on Pd@Pt-PEG-Ce6 for enhanced photodynamic therapy by modulating tumor hypoxia microenvironment. Adv. Funct. Mater. 2018, 28 , 1706310. [CrossRef]

79. Wang, M.; Chang, M.; Chen, Q.; Wang, D.; Li, C.; Hou, Z.; Lin, J.; Jin, D.; Xing, B. Au2Pt-PEG-Ce6 nanoformulation with dual nanozyme activities for synergistic chemodynamic therapy/phototherapy. Biomaterials 2020, 252, 120093. [CrossRef]

80. Yan, J.; Sun, H.; Li, J.; Qi, W.; Wang, H. A theranostic plaster combining photothermal therapy and photodynamic therapy based on chlorin e6/gold nanorods (Ce6/Au nrs) composite. Colloids Surf. A Physicochem. Eng. Asp. 2018, 537, 460-466. [CrossRef]

81. Kotiaho, A.; Lahtinen, R.; Efimov, A.; Metsberg, H.-K.; Sariola, E.; Lehtivuori, H.; Tkachenko, N.V.; Lemmetyinen, H. Photoinduced charge and energy transfer in phthalocyanine-functionalized gold nanoparticles. J. Phys. Chem. C 2010, 114, 162-168. [CrossRef]

82. Vankayala, R.; Kuo, C.-L.; Sagadevan, A.; Chen, P.-H.; Chiang, C.-S.; Hwang, K.C. Morphology dependent photosensitization and formation of singlet oxygen $(1 \Delta \mathrm{g})$ by gold and silver nanoparticles and its application in cancer treatment. J. Mater. Chem. B 2013, 1, 4379-4387. [CrossRef]

83. Pasparakis, G. Light-induced generation of singlet oxygen by naked gold nanoparticles and its implications to cancer cell phototherapy. Small 2013, 9, 4130-4134. [CrossRef]

84. Chadwick, S.J.; Salah, D.; Livesey, P.M.; Brust, M.; Volk, M. Singlet oxygen generation by laser irradiation of gold nanoparticles. J. Phys. Chem. C 2016, 120, 10647-10657. [CrossRef]

85. Zhao, T.; Shen, X.; Li, L.; Guan, Z.; Gao, N.; Yuan, P.; Yao, S.Q.; Xu, Q.-H.; Xu, G.Q. Gold nanorods as dual photo-sensitizing and imaging agents for two-photon photodynamic therapy. Nanoscale 2012, 4, 7712-7719. [CrossRef]

86. Jiang, C.; Zhao, T.; Yuan, P.; Gao, N.; Pan, Y.; Guan, Z.; Zhou, N.; Xu, Q.-H. Two-photon induced photoluminescence and singlet oxygen generation from aggregated gold nanoparticles. ACS Appl. Mater. Interfaces 2013, 5, 4972-4977. [CrossRef] [PubMed]

87. Lazarides, A.A.; Lance Kelly, K.; Jensen, T.R.; Schatz, G.C. Optical properties of metal nanoparticles and nanoparticle aggregates important in biosensors. J. Mol. Struct. THEOCHEM 2000, 529, 59-63. [CrossRef]

88. Albanese, A.; Chan, W.C.W. Effect of gold nanoparticle aggregation on cell uptake and toxicity. ACS Nano 2011, 5, 5478-5489. [CrossRef] [PubMed]

89. Yang, Y.; Hu, Y.; Du, H.; Wang, H. Intracellular gold nanoparticle aggregation and their potential applications in photodynamic therapy. Chem. Commun. 2014, 50, 7287-7290. [CrossRef] 
90. Vankayala, R.; Huang, Y.-K.; Kalluru, P.; Chiang, C.-S.; Hwang, K.C. First demonstration of gold nanorods-mediated photodynamic therapeutic destruction of tumors via near infra-red light activation. Small 2014, 10, 1612-1622. [CrossRef]

91. Vijayaraghavan, P.; Liu, C.-H.; Vankayala, R.; Chiang, C.-S.; Hwang, K.C. Designing multi-branched gold nanoechinus for nir light activated dual modal photodynamic and photothermal therapy in the second biological window. Adv. Mater. 2014, 26, 6689-6695. [CrossRef]

92. Boyer, J.-C.; van Veggel, F.C.J.M. Absolute quantum yield measurements of colloidal NaYF4: Er3+, Yb3+ upconverting nanoparticles. Nanoscale 2010, 2, 1417-1419. [CrossRef]

93. Li, S.; Gu, K.; Wang, H.; Xu, B.; Li, H.; Shi, X.; Huang, Z.; Liu, H. Degradable holey palladium nanosheets with highly active 1d nanoholes for synergetic phototherapy of hypoxic tumors. J. Am. Chem. Soc. 2020, 142, 5649-5656. [CrossRef]

94. Vankayala, R.; Kuo, C.-L.; Nuthalapati, K.; Chiang, C.-S.; Hwang, K.C. Nucleus-targeting gold nanoclusters for simultaneous in vivo fluorescence imaging, gene delivery, and nir-light activated photodynamic therapy. Adv. Funct. Mater. 2015, 25, 5934-5945. [CrossRef]

95. Chen, Q.; Chen, J.; Yang, Z.; Zhang, L.; Dong, Z.; Liu, Z. NIR-II light activated photodynamic therapy with protein-capped gold nanoclusters. Nano Res. 2018, 11, 5657-5669. [CrossRef]

96. Yu, Y.; Geng, J.; Ong, E.Y.X.; Chellappan, V.; Tan, Y.N. Bovine serum albulmin protein-templated silver nanocluster (BSA-Ag13): An effective singlet oxygen generator for photodynamic cancer therapy. Adv. Heal. Mater. 2016, 5, 2528-2535. [CrossRef] [PubMed]

97. Yang, Y.; Chen, M.; Wang, B.; Wang, P.; Liu, Y.; Zhao, Y.; Li, K.; Song, G.; Zhang, X.-B.; Tan, W. NIR-II driven plasmon-enhanced catalysis for a timely supply of oxygen to overcome hypoxia-induced radiotherapy tolerance. Angew. Chem. Int. Ed. 2019, 58, 15069-15075. [CrossRef] [PubMed]

98. Liu, X.; Wan, Y.; Jiang, T.; Zhang, Y.; Huang, P.; Tang, L. Plasmon-activated nanozymes with enhanced catalytic activity by near-infrared light irradiation. Chem. Commun. 2020, 56, 1784-1787. [CrossRef] [PubMed]

99. Liu, P.; Yang, W.; Shi, L.; Zhang, H.; Xu, Y.; Wang, P.; Zhang, G.; Chen, W.R.; Zhang, B.; Wang, X. Concurrent photothermal therapy and photodynamic therapy for cutaneous squamous cell carcinoma by gold nanoclusters under a single NIR laser irradiation. $J$. Mater. Chem. B 2019, 7, 6924-6933. [CrossRef]

100. Sakamoto, M.; Tachikawa, T.; Fujitsuka, M.; Majima, T. Photochemical reactivity of gold clusters: Dependence on size and spin multiplicity. Langmuir 2009, 25, 13888-13893. [CrossRef]

101. Das, T.; Ghosh, P.; Shanavas, M.S.; Maity, A.; Mondal, S.; Purkayastha, P. Protein-templated gold nanoclusters: Size dependent inversion of fluorescence emission in the presence of molecular oxygen. Nanoscale 2012, 4, 6018-6024. [CrossRef]

102. Cui, M.; Zhao, Y.; Song, Q. Synthesis, optical properties and applications of ultra-small luminescent gold nanoclusters. Trends Anal. Chem. 2014, 57, 73-82. [CrossRef]

103. Lillo, C.R.; Calienni, M.N.; Rivas Aiello, B.; Prieto, M.J.; Rodriguez Sartori, D.; Tuninetti, J.; Toledo, P.; Alonso, S.D.V.; Moya, S.; Gonzalez, M.C.; et al. BSA-capped gold nanoclusters as potential theragnostic for skin diseases: Photoactivation, skin penetration, in vitro, and in vivo toxicity. Mater. Sci. Eng. C 2020, 112, 110891. [CrossRef]

104. Poderys, V.; Jarockyte, G.; Bagdonas, S.; Karabanovas, V.; Rotomskis, R. Protein-stabilized gold nanoclusters for PDT: ROS and singlet oxygen generation. J. Photochem. Photobiol. B Biol. 2020, 204, 111802. [CrossRef]

105. Sies, H.; Menck, C.F.M. Singlet oxygen induced DNA damage. Mutat. Res./DNAging 1992, 275, 367-375. [CrossRef]

106. Ravanat, J.-L.; Di Mascio, P.; Martinez, G.R.; Medeiros, M.H.G.; Cadet, J. Singlet oxygen induces oxidation of cellular DNA*. J. Biol. Chem. 2000, 275, 40601-40604. [CrossRef] [PubMed]

107. Chen, Q.; Chen, J.; Liang, C.; Feng, L.; Dong, Z.; Song, X.; Song, G.; Liu, Z. Drug-induced co-assembly of albumin/catalase as smart nano-theranostics for deep intra-tumoral penetration, hypoxia relieve, and synergistic combination therapy. J. Control. Release Off. J. Control. Release Soc. 2017, 263, 79-89. [CrossRef]

108. Kong, N.; Zhang, H.; Feng, C.; Liu, C.; Xiao, Y.; Zhang, X.; Mei, L.; Kim, J.S.; Tao, W.; Ji, X. Arsenene-mediated multiple independently targeted reactive oxygen species burst for cancer therapy. Nat. Commun. 2021, 12, 4777. [CrossRef] [PubMed]

109. Zhen, W.; Liu, Y.; Jia, X.; Wu, L.; Wang, C.; Jiang, X. Reductive surfactant-assisted one-step fabrication of a BiOI/BiOIO3 heterojunction biophotocatalyst for enhanced photodynamic theranostics overcoming tumor hypoxia. Nanoscale Horiz. 2019, 4, 720-726. [CrossRef]

110. Guo, Z.; Zhu, S.; Yong, Y.; Zhang, X.; Dong, X.; Du, J.; Xie, J.; Wang, Q.; Gu, Z.; Zhao, Y. Synthesis of BSA-coated BiOI@Bi2S3 semiconductor heterojunction nanoparticles and their applications for radio/photodynamic/photothermal synergistic therapy of tumor. Adv. Mater. 2017, 29, 1704136. [CrossRef] [PubMed]

111. Kang, Y.; Li, Z.; Yang, Y.; Su, Z.; Ji, X.; Zhang, S. Antimonene nanosheets-based z-scheme heterostructure with enhanced reactive oxygen species generation and photothermal conversion efficiency for photonic therapy of cancer. Adv. Healthc. Mater. 2021, 10, 2001835. [CrossRef]

112. Pan, C.; Ou, M.; Cheng, Q.; Zhou, Y.; Yu, Y.; Li, Z.; Zhang, F.; Xia, D.; Mei, L.; Ji, X. Z-scheme Heterojunction functionalized pyrite Nanosheets for modulating tumor microenvironment and strengthening photo/Chemodynamic therapeutic effects. Adv. Funct. Mater. 2020, 30, 1906466. [CrossRef]

113. Cheng, Y.; Kong, X.; Chang, Y.; Feng, Y.; Zheng, R.; Wu, X.; Xu, K.; Gao, X.; Zhang, H. Spatiotemporally synchronous oxygen self-supply and reactive oxygen species production on z-scheme heterostructures for hypoxic tumor therapy. Adv. Mater. 2020, 32, 1908109. [CrossRef] 
114. Wang, Q.; Ji, Y.; Shi, J.; Wang, L. NIR-driven water splitting H2 production nanoplatform for H2-mediated cascade-amplifying synergetic cancer therapy. ACS Appl. Mater. Interfaces 2020, 12, 23677-23688. [CrossRef]

115. Sang, D.; Wang, K.; Sun, X.; Wang, Y.; Lin, H.; Jia, R.; Qu, F. NIR-driven intracellular photocatalytic O2 evolution on Z-scheme Ni3S2/Cu1.8S@HA for hypoxic tumor therapy. ACS Appl. Mater. Interfaces 2021, 13, 9604-9619. [CrossRef]

116. Chang, M.; Hou, Z.; Wang, M.; Wang, M.; Dang, P.; Liu, J.; Shu, M.; Ding, B.; Al Kheraif, A.A.; Li, C.; et al. Cu2MoS4/Au heterostructures with enhanced catalase-like activity and photoconversion efficiency for primary/metastatic tumors eradication by phototherapy-induced immunotherapy. Small 2020, 16, 1907146. [CrossRef] [PubMed]

117. Yang, D.; Gulzar, A.; Yang, G.; Gai, S.; He, F.; Dai, Y.; Zhong, C.; Yang, P. Au nanoclusters sensitized black TiO2-x nanotubes for enhanced photodynamic therapy driven by near-infrared light. Small 2017, 13, 1703007. [CrossRef] [PubMed]

118. Li, Y.; Wang, L.; Kang, K.; Ma, Y.; Yu, K.; Lu, T.; Qu, F.; Lin, H. All in one theranostic nanoagent based on MoSe2/Au@PEG hollow nanospheres for the enhanced synergetic antitumor. Chem. Eng. J. 2022, 429, 132330. [CrossRef]

119. Zhang, Z.; Huang, J.; Fang, Y.; Zhang, M.; Liu, K.; Dong, B. A nonmetal plasmonic Z-scheme photocatalyst with UV- to NIR-driven photocatalytic protons reduction. Adv. Mater. 2017, 29, 1606688. [CrossRef]

120. Xiao, L.; Liu, T.; Zhang, M.; Li, Q.; Yang, J. Interfacial construction of zero-dimensional/one-dimensional g-C3N4 nanoparticles/ TiO2 nanotube arrays with Z-scheme heterostructure for improved photoelectrochemical water splitting. ACS Sustain. Chem. Eng. 2019, 7, 2483-2491. [CrossRef]

121. Kou, Z.; Zhao, P.; Wang, Z.; Jin, Z.; Chen, L.; Su, B.-L.; He, Q. Acid-responsive H2-releasing Fe nanoparticles for safe and effective cancer therapy. J. Mater. Chem. B 2019, 7, 2759-2765. [CrossRef] [PubMed]

122. Fan, M.; Wen, Y.; Ye, D.; Jin, Z.; Zhao, P.; Chen, D.; Lu, X.; He, Q. Acid-responsive H2-releasing 2D MgB2 nanosheet for therapeutic synergy and side effect attenuation of gastric cancer chemotherapy. Adv. Healthc. Mater. 2019, 8, 1900157. [CrossRef]

123. Garcia-Peiro, J.I.; Bonet-Aleta, J.; Bueno-Alejo, C.J.; Hueso, J.L. Recent advances in the design and photocatalytic enhanced performance of gold plasmonic nanostructures decorated with non-titania based semiconductor hetero-nanoarchitectures. Catalysts 2020, 10, 1459. [CrossRef]

124. Clavero, C. Plasmon-induced hot-electron generation at nanoparticle/metal-oxide interfaces for photovoltaic and photocatalytic devices. Nat. Photonics 2014, 8, 95-103. [CrossRef]

125. Ortega-Liebana, M.C.; Bonet-Aleta, J.; Hueso, J.L.; Santamaria, J. Gold-based nanoparticles on amino-functionalized mesoporous silica supports as nanozymes for glucose oxidation. Catalysts 2020, 10, 333. [CrossRef]

126. Luo, W.; Zhu, C.; Su, S.; Li, D.; He, Y.; Huang, Q.; Fan, C. Self-catalyzed, self-limiting growth of glucose oxidase-mimicking gold nanoparticles. ACS Nano 2010, 4, 7451-7458. [CrossRef]

127. Huo, M.; Wang, L.; Chen, Y.; Shi, J. Tumor-selective catalytic nanomedicine by nanocatalyst delivery. Nat. Commun. 2017, 8, 357. [CrossRef] 